\title{
Synaptic Interactions among Excitatory Afferents to Nucleus Accumbens Neurons: Hippocampal Gating of Prefrontal Cortical Input
}

\author{
Patricio O'Donnell and Anthony A. Grace \\ Departments of Neuroscience and Psychiatry, Center for Neuroscience, University of Pittsburgh, Pittsburgh, \\ Pennsylvania 15260
}

The interactions among excitatory inputs arising from the prefrontal cortex, amygdala, and hippocampus, and innervating nucleus accumbens neurons were studied using in vivo intracellular recording techniques. Neurons recorded in the accumbens displayed one of three activity states: (1) silent, (2) spontaneously firing at low, constant rates, or (3) a bistable membrane potential, characterized by alternating periods of activity and silence occurring in concert with spontaneous transitions between two steady-state membrane potentials (average, $-77.3+7.1 \mathrm{mV}$ base, $-63.0+$ $7.4 \mathrm{mV}$ plateau). These neurons also exhibited a high degree of convergence of responses elicited by stimulation of each of the three excitatory inputs tested. Activation of hippocampal afferents, but not cortical, amygdaloid, or thalamic afferents, induced bistable cells to switch to the depolarized (active) state. In contrast, no bistable cells were encountered in the nucleus accumbens following an acute transection of the fornix. Furthermore, microinjection of lidocaine in the vicinity of the hippocampal afferents at the level of the fornix caused a reversible elimination of the plateau phase in bistable cells. These data suggest that hippocampal input is necessary for accumbens neurons to enter a depolarized, active state. Furthermore, activation of prefrontal cortical inputs fail to evoke spike firing in accumbens neurons unless they are in this active state. Consequently, the hippocampus appears to be capable of gating prefrontal corticoaccumbens throughput.

[Key words: accumbens, intracellular recordings, in vivo, prefrontal cortex, hippocampus, amygdala, fornix, schizophrenia, striatum, electrophysiology]

Based on its anatomical interconnections, the nucleus accumbens is proposed to be involved in the coordination of limbic and motor systems (Mogenson et al., 1980; Mogenson and Yang, 1991). This structure has received increasing attention in recent years, particularly with regard to its possible involvement in the genesis and treatment of schizophrenia. It is generally believed

\footnotetext{
Received Sept. 7, 1994; revised Nov. 22, 1994; accepted Dec. 5, 1994.

We thank Mr. Dave Harden for helpful suggestions, Dr. Antonieta Lavín for comments on the manuscript, and Mr. Mark Antkowiak for his excellent technical assistance. This work was supported by USPHS MH45156, MH42217, and NS19608 (A.A.G.) and by the Scottish Rite Schizophrenia Research Program (A.A.G. and P.O.).

Correspondence should be addressed to Patricio O'Donnell, M.D., Ph.D., Department of Neuroscience, 446 Crawford Hall, University of Pittsburgh, Pittsburgh, PA 15260.
}

Copyright (C) 1995 Society for Neuroscience $\quad 0270-6474 / 95 / 153622-18 \$ 05.00 / 0$ that alterations in dopamine (D $\Lambda$ ) neurotransmission are in volved in schizophrenic symptoms, as shown by pharmacological evidence such as the ability of drugs which increase DA levels (e.g., amphetamine, L-DOPA, or cocaine) to induce a schizophrenia-like state in controls (Snyder, 1973), and the finding that the therapeutic efficacy of antipsychotic drugs is highly correlated with their ability to block $\mathrm{DA} \mathrm{D}_{2}$ receptors (Seeman, 1987). Furthermore, antipsychotic drugs have been proposed to exert their therapeutic actions by inducing depolarization block in the dopamine (DA)-containing cells located in the anterior ventral tegmental area (VTA) (Chiodo and Bunney, 1983; White and Wang, 1983; Grace, 1992) which project preferentially to the accumbens (Groenewegen et al., 1980). Nonetheless, investigations to date have failed to find substantial evidence for a primary disruption of the DA system itself in schizophrenia (Grace, 1991; Carpenter and Buchanan, 1994). On the other hand, there is substantial evidence that a pathological change in the prefrontal cortex may contribute to this disorder, including (1) a reduction in regional cerebral blood flow ( $\mathrm{CBF}$ ) in the dorsolateral aspect of the prefrontal cortex (PFC) of schizophrenics (Buchsbaum et al., 1982; Berman et al., 1986; Friston, 1992; Liddle et al., 1992a,b), even in never-medicated patients (Buchsbaum et al., 1992); (2) poor performance in neuropsychological tests sensitive to PFC function (Liddle and Morris, 1991; Raine et al., 1992); (3) structural deficits observed with magnetic resonance imaging (MRI) (Raine et al., 1992); (4) a reduction in the release of GABA and glutamate in PFC tissue obtained from schizophrenics (Sherman et al., 1991); and (5) alterations in phosphomonoesters in the frontal cortical fibers as shown by in vivo $\mathrm{P}^{30}$ magnetic resonance spectroscopy (Pettegrew et al., 1991). However, despite the preponderance of evidence for a disruption in PFC activity in schizophrenia (Robbins, 1990; Berman and Weinberger, 1991; Weinberger et al., 1992), reports of cellular or structural pathology in this region have been inconclusive (Weinberger, 1987; Shapiro, 1993). On the other hand, several studies have provided evidence for anatomical disruptions occurring in the amygdala-entorhinal complex (Arnold et al., 1991) and in the hippocampus (Kovelman and Scheibel, 1984; Falkai and Bogerts, 1986) in this disorder. A potential involvement of these structures is further supported by MRI studies of schizophrenics in which a reduction in the size of the left temporal lobe has been reported (Barta et al., 1990; Suddath et al., 1990; Shenton et al., 1992; Bogerts et al., 1993; Gur and Pearlson, 1993; Kawasaki et al., 1993; Waddington, 1993) and by PET studies revealing the presence of diminished 
metabolic activity in the hippocampus of schizophrenics (Tamminga et al., 1992).

The physiological properties of nucleus accumbens neurons have becn well characterized in vitro in the brain slice preparation, where they have been shown to have a very polarized membrane potential and exhibit EPSPs in response to stimulation of cortical, hippocampal, and amygdaloid afferents (Chang and Kitai, 1986; Uchimura et al., 1989a; Meredith et al., 1993; O'Donnell and Grace, 1993b, 1994a; Pennartz et al., 1993; Kombian and Malenka, 1994). However, because these regions do not lie in a single plane within the accumbens, at least some of these afferent processes are transected during preparation of the brain slices prior to recording. Furthermore, due to the absence of spontaneously discharging cortical neurons in the slice, nucleus accumbens neurons do not exhibit spontaneous EPSPs or spike activity in vitro. As a result, it is difficult to assess how afferent systems interact to drive the spontaneous spike firing that is present in nucleus accumbens neurons in the intact brain.

In addition to having one of the densest DA innervations in the brain (Johansson and Hökfelt, 1981), the nucleus accumbens receives massive inputs from the $\mathrm{PFC}$, the hippocampus (mainly the ventral subiculum), and the amygdala (Swanson and Cowan, 1975; Groenewegen et al., 1980; Kelley and Domesick, 1982; De France et al., 1985; Sesack et al., 1989; Kita and Kitai, 1990). Although there are numerous studies showing the modulatory actions produced by DA and VTA stimulation on hippocampal (Reinstein et al., 1982; Yang and Mogenson, 1984, 1986, 1987; Mogenson and Yim, 1991; Meredith et al., 1993; Mittleman et al., 1993), cortical (O’Donnell and Grace, 1994a), and amygdaloid (Yim and Mogenson, 1982, 1986, 1988, 1989) inputs to this region, the interactions between the three primary excitatory afferents (i.e., PFC, amygdala, and hippocampus) have not yet been examined in detail. This investigation focuses on the effects mediated by activation of these inputs on accumbens cell physiology using in vivo intracellular recordings, with an emphasis placed on assessing the degree of convergence of these inputs upon single neurons within the accumbens. In particular, we examined the contribution of these afferents to driving spontaneous activity states of accumbens cells, including the sudden, 10-20 $\mathrm{mV}$ switches in the membrane potential that persist for hundreds of milliseconds as first described by Yim and Mogenson (1988). This bistable pattern of activity is similar to that reported for dorsal striatal cells (Hull et al., 1970; Wilson and Groves, 1981; Calabresi et al., 1990; Wilson, 1992a,b, 1993; Onn et al., 1994) and cortical cells (Steriade et al., 1993; Cowan and Wilson, 1994) recorded in vivo, although its origin in any of these structures has not been established conclusively.

Part of this work has been presented in abstract form (Grace and O'Donnell, 1994; O'Donnell and Grace, 1994b).

\section{Materials and Methods}

Animals and surgery. Intracellular recordings of accumbens neurons were obtained in vivo from 24 male Sprague-Dawley adult rats purchased from Zivic-Miller laboratories (Allison Park, PA) and weighing $271-415 \mathrm{gm}$. All experiments were performed in accordance with the Guide for the Care and Use of Laboratory Animals published by the USPHS, with the specific protocols approved by the University of Pittsburgh Institutional Animal Care and Use Committee. The rats were deeply anesthetized with chloral hydrate $(400 \mathrm{mg} / \mathrm{kg}$, i.p.) before being placed in a stereotaxic apparatus (Narishige, Tokyo, Japan). Supplemental anesthetic (chloral hydrate, $1.5 \%$ ) was continuously administered throughout the experiment by means of a microdrip system attached to a cannula located in a lateral tail vein, with the rate of infusion adjusted to maintain a constant level of anesthesia as determined by periodic testing of the hindlimb compression reflex.

Small burr holes were drilled in the skull in order to allow the placement of stimulating and recording electrodes. Bipolar concentric stimulating electrodes (model NE-100X; Rhodes Med. Instr., Woodland Hills, CA) were placed in the prefrontal cortex $(\mathrm{A}+3.0 \mathrm{~mm}, \mathrm{~L} 0.6$ $\mathrm{mm}, \mathrm{H}-5.2 \mathrm{~mm}$; or A $+3.7 \mathrm{~mm}, \mathrm{~L} 1.0 \mathrm{~mm}, \mathrm{H}-2.5 \mathrm{~mm})$, the fornixfimbria (A $-0.3 \mathrm{~mm}, \mathrm{~L} 0.2-0.5 \mathrm{~mm}, \mathrm{H}-6.2 \mathrm{~mm}$ ), the amygdala (A -2.3 to $-2.5 \mathrm{~mm}, \mathrm{~L} 4.9 \mathrm{~mm}, \mathrm{H}-8.5 \mathrm{~mm}$ ), the paraventricular (PV) midline thalamic nucleus ( $\mathrm{A}-2.0 \mathrm{~mm}, \mathrm{~L} 0.1 \mathrm{~mm}, \mathrm{H}-6.0 \mathrm{~mm}$ ), and or the entorhinal cortex (A $-6.5 \mathrm{~mm}, \mathrm{~L} 7.0 \mathrm{~mm}, \mathrm{H}-8.0 \mathrm{~mm})$. All the coordinates were determined using a rat brain stereotaxic atlas (Paxinos and Watson, 1986).

Electrophysiological recordings. Micropipettes were pulled from 1 $\mathrm{mm}$ o.d. Omegadot borosilicate glass tubing (World Precision Instruments, Sarasota, FL) using a $\Gamma$ laming-Brown P-80/PC microelectrode puller and filled with $3 \mathrm{~m}$ potassium acetate. Electrode potentials were amplified by a headstage amplifier connected to a NeuroData intracellular preamplifier (NeuroData IR-283). Current was injected through a bridge circuit integral to the amplifier, and the amplitude of current injected and the membrane potentials recorded were observed on-line on an oscilloscope (Kikusui COS 5042) in addition to being continuously digitized by a NeuroData Neurocorder (DR-390) and stored on VHS videotapes for subsequent off-line analysis. For data analysis, a CED1401 Intelligent Laboratory Interface (Cambridge Electronic Design, Cambridge, UK) connected to a Gateway 486 computer was used, with hardcopies obtained by directing the output to a Hewlett-Packard 7475A digital plotter.

Stimulating pulses with durations of $100-500 \mu \mathrm{sec}$ and intensities between $100 \mu \mathrm{A}$ and $1.5 \mathrm{~mA}$ were delivered using two Grass S88 stimulators connected to Grass PSIU6 constant current stimulus isolation units. After obtaining a stable penetration of a cell, its baseline activity was recorded for a few minutes before applying depolarizing and hyperpolarizing pulses through the recording electrode for assessment of membrane properties. A stable penetration was defined by the presence of (1) a stable resting membrane potential of at least $-55 \mathrm{mV}$, (2) action potentials greater than $45 \mathrm{mV}$ in amplitude, and (3) a train of spikes induced by membrane depolarization. Each cell from which data was collected was recorded in a stable state for a minimum of 5 min.

Firrbria-fornix trursections. A subset of nine cells was recorded from seven animals in which the fimbria-fornix system was transected using a glass microknife constructed from a thickness grade 1 glass coverslip. The microknife was introduced through a slot drilled in the skull at the level of bregma, with the knife oriented $15^{\circ}-30^{\circ}$ caudally as it was inserted to a depth of $5 \mathrm{~mm}$ below the skull surface. Transections were made by moving the knife from the midline to a point $5 \mathrm{~mm}$ lateral to midline, which was subsequently confirmed in histological analysis to completely transect the fornix. After the transection, the rats were allowed to recover for at least $1 \mathrm{hr}$ prior to recording. As a control for the specificity of the transection, an additional group of nine neurons were recorded from two animals bearing a similar cut that was placed so as to cut most of the same fiber bundles but specifically spare the fimbria-fornix system. The section was performed in the same manner as those of the lesion group, except that the fornix was spared by either (1) only lowering the microknife to a ventral position that was $2.5 \mathrm{~mm}$ below the brain surface, or (2) by entering the brain at the same coordinates but with the knife oriented in the vertical plane. Throughout this paper we use the term "fornix" to refer to the fimbria-fornix fiber system. In a similar manner, we have used the term "hippocampal afferents" to refer to those fibers that reach the nucleus accumbens and originated mainly from the ventral and dorsal subiculum and, albeit more sparingly, from the CA 1 and CA4 regions (Kelley and Domesick, 1982; De France et al., 1985).

In a group of animals a 27 gauge cannula was positioned at the same coordinates used for insertion of the stinulating electrodes, which would place the tip of the cannula within the fornix. After obtaining 5 min of stable baseline data from an impaled nucleus accumbens neuron, the effects of reversible interruption of transmission along the fornix was tested by administering $0.1-0.2 \mu \mathrm{l}$ of $1 \%$ lidocaine (Elkins-Sinn, Cherry Hill, NJ) injected through the cannula using a $1 \mu \mathrm{l}$ Hamilton syringe. The effect of lidocaine injection into the fornix was tested in four nucleus accumbens neurons. In addition, the specificity of the response was examined by testing the effects of lidocaine injected into nearby regions on the activity of nucleus accumbens cells. Lidocaine 

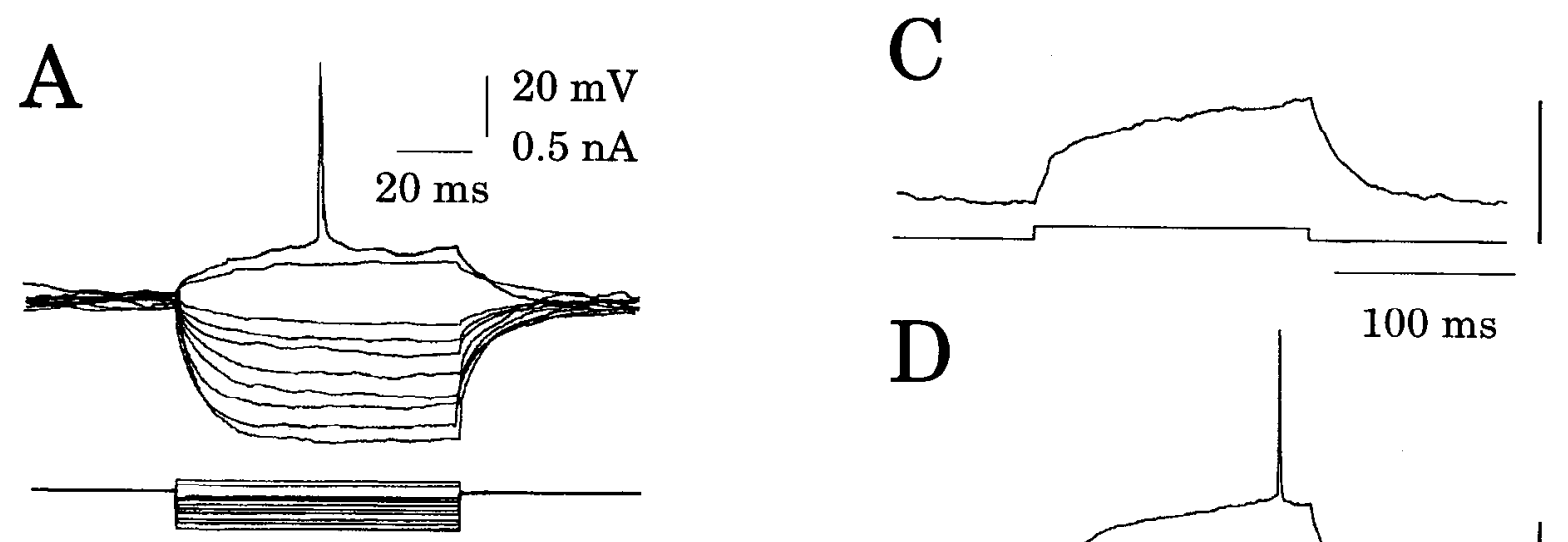

$50 \mathrm{mV}$

$2 \mathrm{nA}$
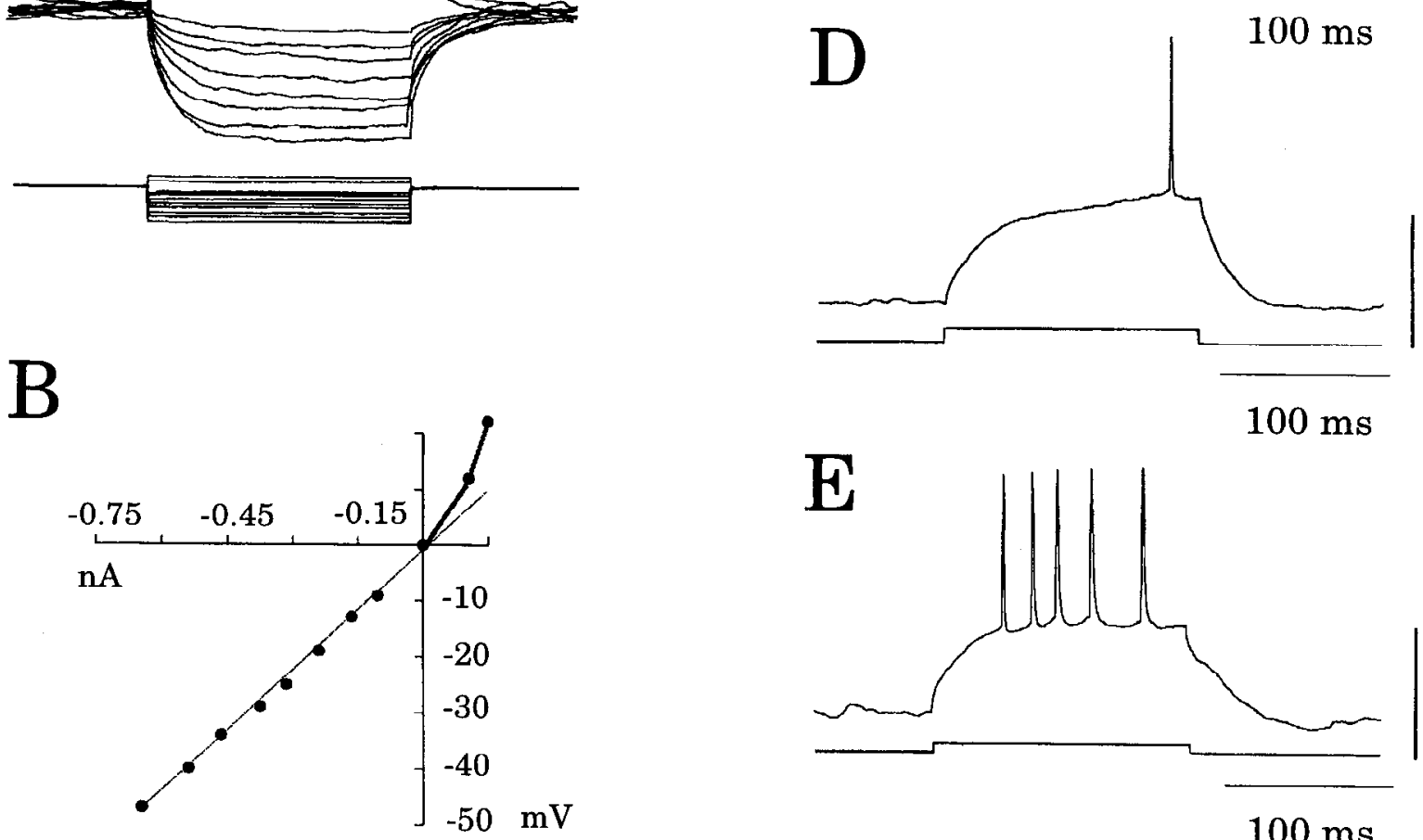

$50 \mathrm{mV}$

$2 \mathrm{nA}$

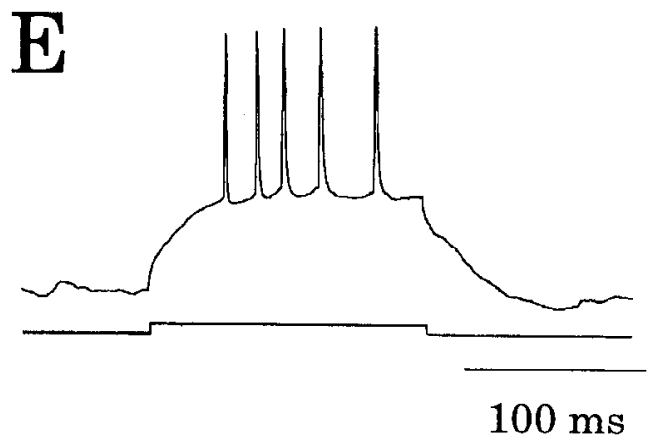

$50 \mathrm{mV}$

$2 \mathrm{nA}$

Figure 1. Nucleus accumbens cells recorded in vivo show several membrane properties that are identical to those observed in vitro. A, Determination of input resistance in accumbens ncurons recorded in vivo. Intracellular injection of $100 \mathrm{msec}$ duration constant current pulses (lower traces) elicits deflections in the membrane potential (upper traces) in this accumbens cell. $B$, The steady-state voltage deflections are plotted against the amplitude of the current pulses injected. The slope of the resultant regression line was used to estimate the input resistance, which in this case was $64 \mathrm{M} \Omega$. In response to depolarizing current injection an inward rectification is observed (RMP, $-85 \mathrm{mV}$ ). $C$, Depolarization of the membrane of accumbens neurons induces a slow depolarization that precedes spike discharge. Injection of low levels of depolarizing current into this nondischarging accumbens neuron elicits a noninactivating slow membrane depolarization that is present throughout the current pulse. $D$, Increased levels of membrane depolarization elicit a slow depolarization that culminates in spike discharge when the depolarization reaches the threshold membrane potential for triggering an action potential (RMP, -79). E. Repetitive discharge evoked by membrane depolarization in another nonfiring cell shows firing-frequency adaptation, in which the interval between spikes increases at later stages of the evoked spike train (MP, $-85 \mathrm{mV}$ and $-65 \mathrm{mV}$ ).

injection into the fornix was also tested for its effects on the activity of bistable cells recorded in the PFC.

Histology. At the completion of each experiment, the animals were given an overdose of pentobarbital intraperitoneally and perfused rapidly with ice-cold saline prior to perfusion with $10 \%$ buffered formalin. The brains were then removed and fixed overnight in the formalin solution. After fixation, the brains were incubated in phosphate buffer, and $70 \mu \mathrm{m}$ thick sections were cut using a microtome. The sections were then mounted and stained with cresyl violet. All recording and stimulating electrode locations, as well as the site of cannula placement and the extent of the fornix transection, were identified according to a rat brain stereotaxic atlas (Paxinos and Watson, 1986). In order to aid in the identification and reconstruction of the recording microelectrode tracks, a maximum of four penetrations was performed in each animal.

\section{Results}

In vivo intracellular recordings were performed from a total of 60 nucleus accumbens neurons in 24 rats: 42 cells were recorded in 15 untreated rats, nine cells following acute transection of the fimbria-fornix in seven rats, and nine cells from two rats that had received a sham lesion. The analysis was limited to data that had been obtained from cells that exhibited a stable resting membrane potential of at least $-55 \mathrm{mV}$, displayed action poten- tials that were $45 \mathrm{mV}$ or greater in amplitude as measured from the beginning of the fast-rising phase to the spike peak, and in which subsequent histological analyses showed they were located within the anatomical boundaries of the nucleus accumbens. Although no systematic attempt was made to identify whether the cells recorded were located in the core or the shell region of the accumbens, most of the electrode tracks were found in the medial aspect of the accumbens, suggesting unar cells in the shell region were preferentially sampled.

\section{Passive membrane properties}

The resting membrane potential of the neurons recorded in intact animals averaged $-74.8 \pm 10.2 \mathrm{mV}$ (mean $\pm \mathrm{SD}$; range, -95 to $-55 \mathrm{mV}, n-42$ ). The input resistance was estimated by injecting a series of $100 \mathrm{msec}$ hyperpolarizing current pulses into the neurons and plotting the amplitude of the current pulse against the membrane potential deflections it produced. The points obtained were fitted to a least squares regression line, with the input resistance for each neuron calculated from the slope of the line (Fig. 1). The input resistance of nucleus accumbens 
cells averaged $54.3 \pm 18.3 \mathrm{M} \Omega$ (range, 22.7-116.8 $\mathrm{M} \Omega n=$ 27). The membrane time constant ( $\tau$ ) was estimated by injecting a $-0.2 \mathrm{nA}$ hyperpolarizing pulse and measuring the time required for the membrane potential to reach $63 \%$ of the maximal deflection produced; this yielded a $\tau$ which averaged $6.8 \pm 2.8$ msec (range, $2.7-10.9 \mathrm{msec}, n=24$ ). In 12 of $20 \mathrm{cclls}$, the $I / \mathrm{V}$ plot (Fig. $1 B$ ) revealed an inward rectification in the depolarizing direction similar to that shown for accumbens neurons recorded in vitro (O'Donnell and Grace, 1993b), which was correlated with the presence of a slow depolarization preceding spike discharge. In addition, seven of nine neurons also exhibited an inward rectification in the hyperpolarizing direction when the amplitude of the current injected was higher than $-0.5 \mathrm{nA}$, which is consistent with that reported for in vitro recordings from accumbens neurons (Uchimura et al., 1989a; O'Donnell and Grace, 1993b).

\section{Spike generation}

Action potentials in accumbens neurons occurred spontaneously or could be evoked by direct depolarization of the membrane by intracellular current injection (Fig. 1). Spike amplitudes averaged $61.3 \pm 9.4 \mathrm{mV}$ (range, $48-85.8 \mathrm{mV}, n-42$ ), and the membrane potential threshold at which spikes were triggered was $-59.8 \pm 8.1 \mathrm{mV}$ (range, -82.0 to $-38.7 \mathrm{mV}, n=42$ ). As observed in vitro (O'Donnell and Grace, 1993b), a slow depolarization of the membrane preceded both spontaneously occurring and (in 19 of 30 cells) depolarization-induced action potential discharge (Fig. 1C,D). Furthermore, firing-frequency adaptation was observed in 15 of the 23 cells tested (Fig. $1 E$ ).

A slow spike resembling the low threshold spikes (LTS) described in other preparations (Jahnsen and Llinás, 1984) could be evoked in 10 of 24 cells tested. This LTS could be triggered by hyperpolarizing the membrane prior to applying a depolarizing current pulse. The LTS consisted of a slowly rising and slowly falling low-amplitude all-or-none potential that often was of sufficient amplitude to trigger action potential discharge (Fig. $2 A, B)$. The LTS was also triggered in neurons with a depolarized membrane potential as a rebound following a brief membrane hyperpolarization (Fig. 2C).

\section{Spontaneous activity}

Approximately $75 \%$ (39 of 51) of the cells recorded in both the intact and sham-lesioned groups exhibited spontaneous spike discharge (Fig. $3 A, B, E$ ), although their firing rate was comparatively low $(3.8 \pm 4.1 \mathrm{~Hz}$; range, $0.1-14.9 \mathrm{IIz} ; n=39)$. The remaining cells did not discharge action potentials spontaneously, although synaptic responses could he evoked hy stimulation of the prefrontal cortex in all cells tested. In addition, 59\% (30 of 51) of the cells recorded (25 spontaneously active, 5 nonfiring), exhibited rapid, large-amplitude spontaneous shifts in membrane potential, with the shifts occurring between two relatively stable membrane potentials separated by $8-22 \mathrm{mV}(n=$ $30 ; 24$ in intact, 6 in sham; Fig. $3 A, B$ ). This corresponded to the average difference between basal membrane potentials $(-77.3$ $\pm 7.1 \mathrm{mV}$; range, -64 to $-95 \mathrm{mV} ; n=30$ ) and plateau membrane potentials $(-63.0 \pm 7.4 \mathrm{mV}$; range, -50 to $-78 \mathrm{mV}, n$ $=30$ ), respectively. The presence of a bistable event was defined as a rapid transition in membrane potential occurring with a rise time of $5 \mathrm{mV} / \mathrm{msec}$ or greater, and achieving a plateau depolarization within the range of $8-22 \mathrm{mV}$ depolarized to the RMP, with the depolarization being maintained for a minimum of 100 msec (Fig. 3B). This criterion was employed in each case in
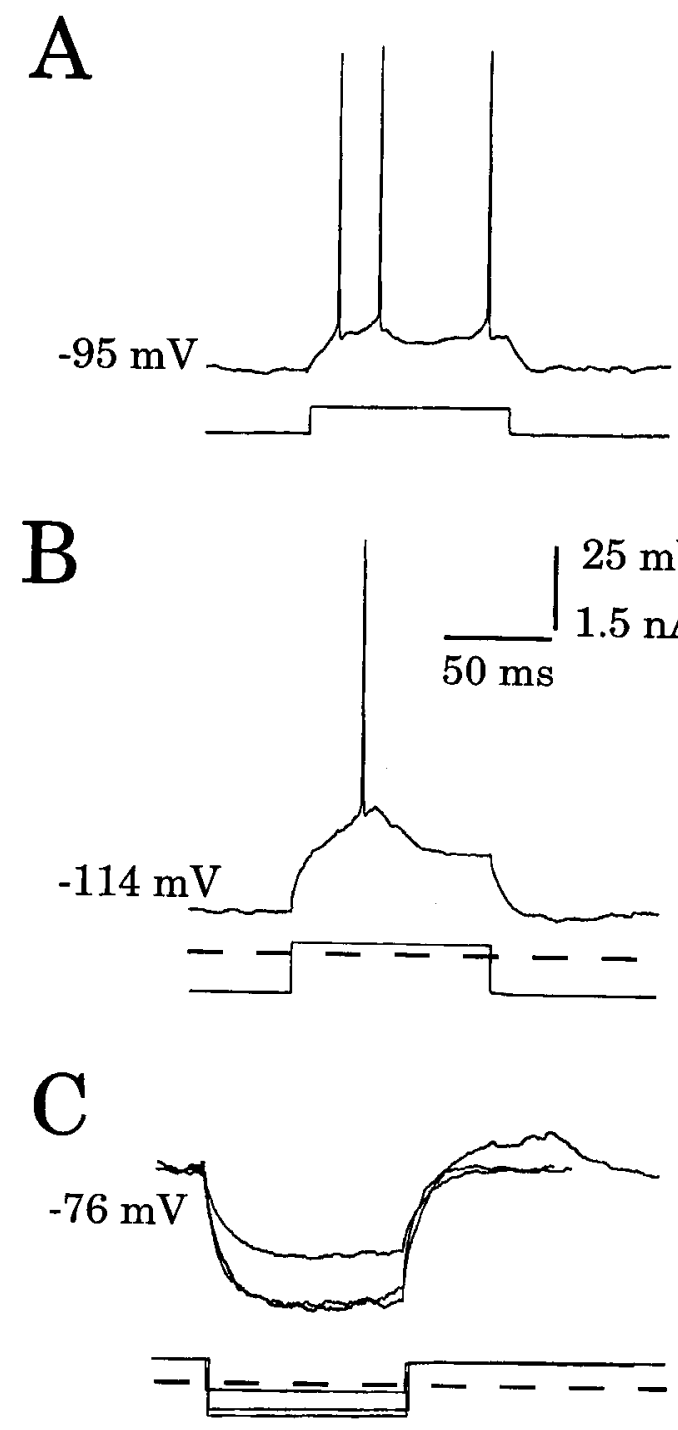

Figure 2. Low-threshold spikes can be evoked by membrane polarization in accumbens neurons. $A$, Depolarization of the membrane of an accumbens neuron at resting membrane potential typically triggers repctitive action potential discharge. $B$, Ilowever, if the membrane of the same neuron is first hyperpolarized by $10-20 \mathrm{mV}$, subsequent depolarizing current pulses will elicit a slow, all-or-none depolarization that in this neuron triggers spike discharge. This slow event resembles the low-threshold spikes described elsewhere in terms of its voltage dependency and all-or-none nature (RMP, $-95 \mathrm{mV}$ ). $C$, Conversely, if the membrane of this neuron is first depolarized by $7-15 \mathrm{mV}$ from rest, injection of brief hyperpolarizing pulses at increasing amplitudes will evoke rebound all-or-none depolarizing events. The all-or-none nature of this event can be observed in this case, since only one of two nearly equal-amplitude hyperpolarizing pulses is shown to evoke the rebound LTS (RMP, $-83 \mathrm{mV}$ ).

which quantitative descriptions of the properties of the bistable events is presented. Events that met this criteria could be readily distinguished from spontaneously occurring EPSPs, since the latter were typically much smaller in amplitude and did not maintain a stable depolarized potential, but instead rapidly decayed after achieving its maximal depolarization. The continuous presence of these bistable states of the membrane potential can further be observed by constructing a time histogram of the membrane potential of individual cells that encompassed periods of 20-30 sec of recording. In each case, cells classified as bistable exhibited a bimodal distribution in the membrane potential, 

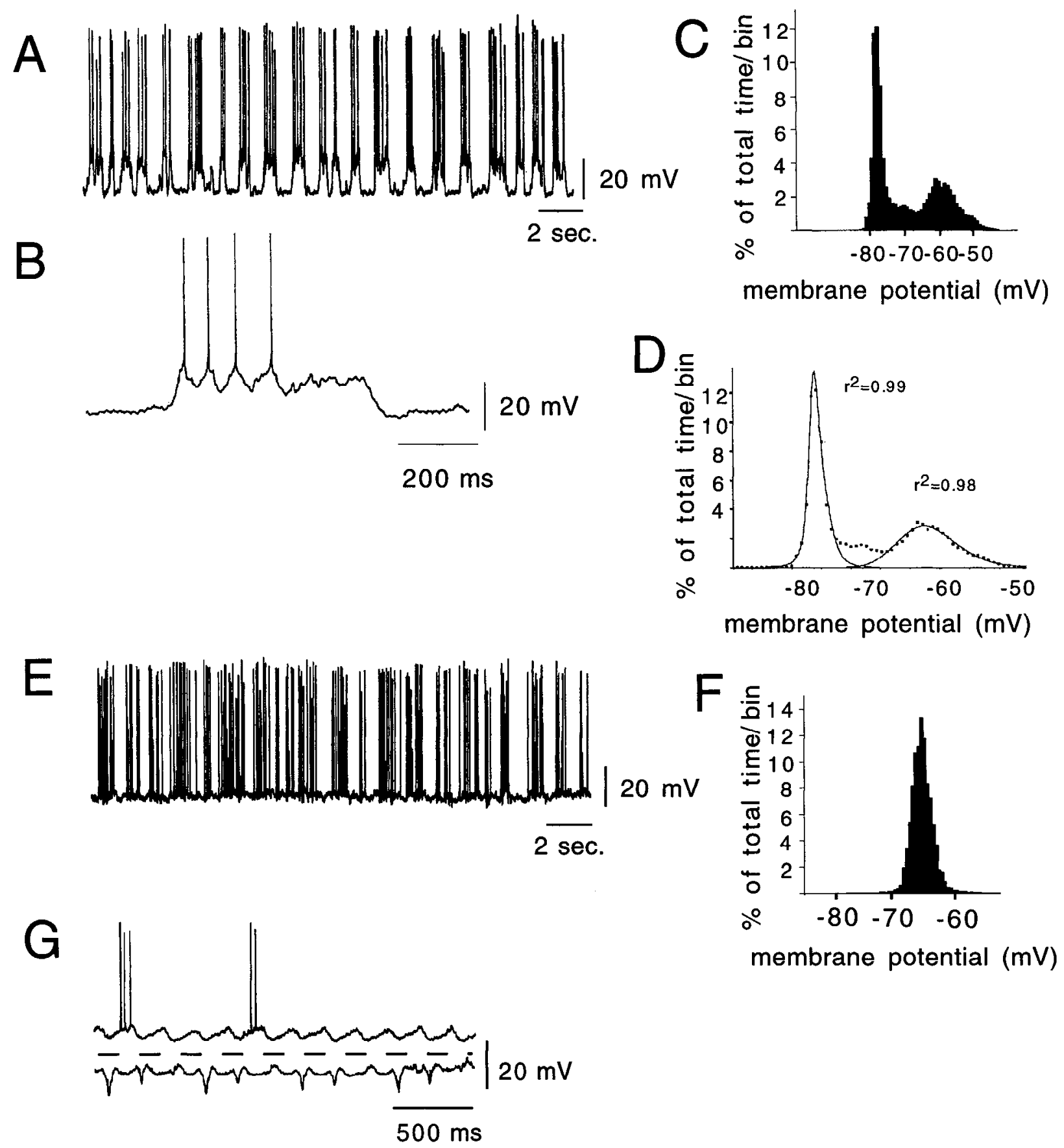

Figure 3. Most of the nucleus accumbens neurons recorded in vivo fired spontaneously with one of two distinct discharge patterns: bistable and continuous. A, The bistable pattern of activity is characterized by the presence of rapid spontaneous shifts in the steady-state membrane potential. Rapid switches in membrane potential that were nearly $20 \mathrm{mV}$ in amplitude are observed to move the cell between two clearly distinguishable stable states. Action potential discharge occurs only when the membrane is in the depolarized state (MP oscillated between -78 $\mathrm{mV}$ and $-60 \mathrm{mV}$ ). $B$, Observed at a faster time base, the components of a plateau depolarization are illustrated. $C$, Time-frequency histogram showing the number of $0.1 \mathrm{msec}$ bins during which the membrane was at the potential indicated; total record length from $A$, 20 sec. The $y$-axis has been converted to show the results in terms of the percent of the $20 \mathrm{sec}$ period spent at the membrane potential shown. A bimodal distribution is present, with the two modes representing the two membrane potential states. $D$, The data surrounding each peak of the histogram in $C$ (i.e., the maximum amount of time spent at each membrane potential) can be fitted to two normal functions with high coefficients of determination $\left(r^{2}\right) . E$, A smaller proportion of spontaneously firing cells exhibited a continuous irregular slow firing frequency. No spontaneous transitions in activity states were observed in these neurons (RMP, $-76 \mathrm{mV}$ ). $F$, The membrane potential frequency histogram obtained from the tracing in $E$ shows a normal distribution. $G$, Several nucleus accumbens neurons exhibited $5-8 \mathrm{~Hz}$ oscillations in the membrane potential. A $6 \mathrm{~Hz}$ oscillation of the membrane potential of this accumbens neuron recorded at RMP ( $-55 \mathrm{mV}$, upper trace) is not altered in frequency by hyperpolarization of the membrane $(-0.3 \mathrm{nA}$, bottom trace), although the oscillatory events switch to a hyperpolarizing direction. The dashed line indicates $-60 \mathrm{mV}$. 


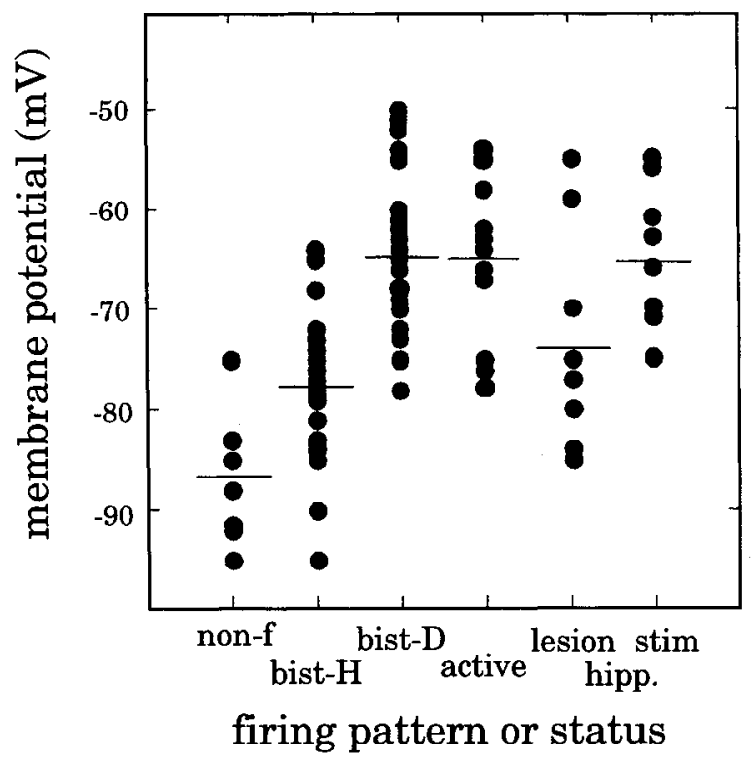

Figure 4. Bistable cells exhibit two steady-state membrane potentials. Membrane potentials are plotted for nonfiring cells (non $f$ ), bistable cells while in the hyperpolarized (bist-H) and depolarized (bist-D) states, and tonically active cells (active). In addition, membrane potentials are plotled for the plateau-like depolarizations induced by formix stimulation (stim), and for the silent cells encountered in the fornixlesioned group (lesion). The means are shown as horizontal bars. When bistable cells are in the hyperpolarized, nonfiring state (bist- $H$ ), the average membrane potential is within the range of that of nonfiring cells in either control (non-f) or fornix-lesioned (lesion) groups. Furthermore, the membrane potentials of bistable cells when they are in the depolarized, discharging state (bist-D) are similar to those of tonically spiking cells (active) or cells recorded during fornix stimulation (stim).

with the peak time spent at membrane potentials that represented the values reported for the resting potential and the depolarized plateau potential. Intermediate values reflect the brief depolarizations presumably due to the presence of EPSPs occurring during both the resting potential and the plateau phase of cell activity. In addition, the values clustered around each of these two modes could be fitted to respective normal curves with an $r^{2}$ of at least 0.95 (Fig. 3D). In contrast, cells which had a constant firing rate did not exhibit such shifts in membrane potential (Fig. $3 E$ ). In these cells, construction of a membrane potential histogram resulted in a normal distribution of potentials around a single peak (Fig. $3 F$ ). Some cells recorded for long periods of time (i.e., 2 hr or longer) were observed to switch back and forth between activity states; for example, a cell that had been firing in a bistable pattern for 12 min would cease spike activity for $38 \mathrm{~min}$ before resuming the bistable state. These changes in pattern were especially apparent when supplemental anesthesia was administered, which caused a substantial slowing of the firing rates and a transition to the hyperpolarized state.

The bistable cells exhibited spiking only during the depolarized state (Fig. $3 A, B$ ), with the spikes often occurring in bursts. The tonically firing cells discharged action potentials at membrane potentials that were not significantly different from those observed at the depolarized state of bistable cells $(-64.6 \pm 6.8$ $\mathrm{mV}$, range, -55 to $-76 \mathrm{mV}, n=14$; Fig. 4). In contrast, the non-firing neurons had a comparatively hyperpolarized membrane potential that was significantly larger than that present during the hyperpolarized state of bistable cells $(-87.1 \pm 6.7$ $\mathrm{mV}$, range, -75 to $-95 \mathrm{mV}, n=7 ; p<0.002$, Student's $t$ test;
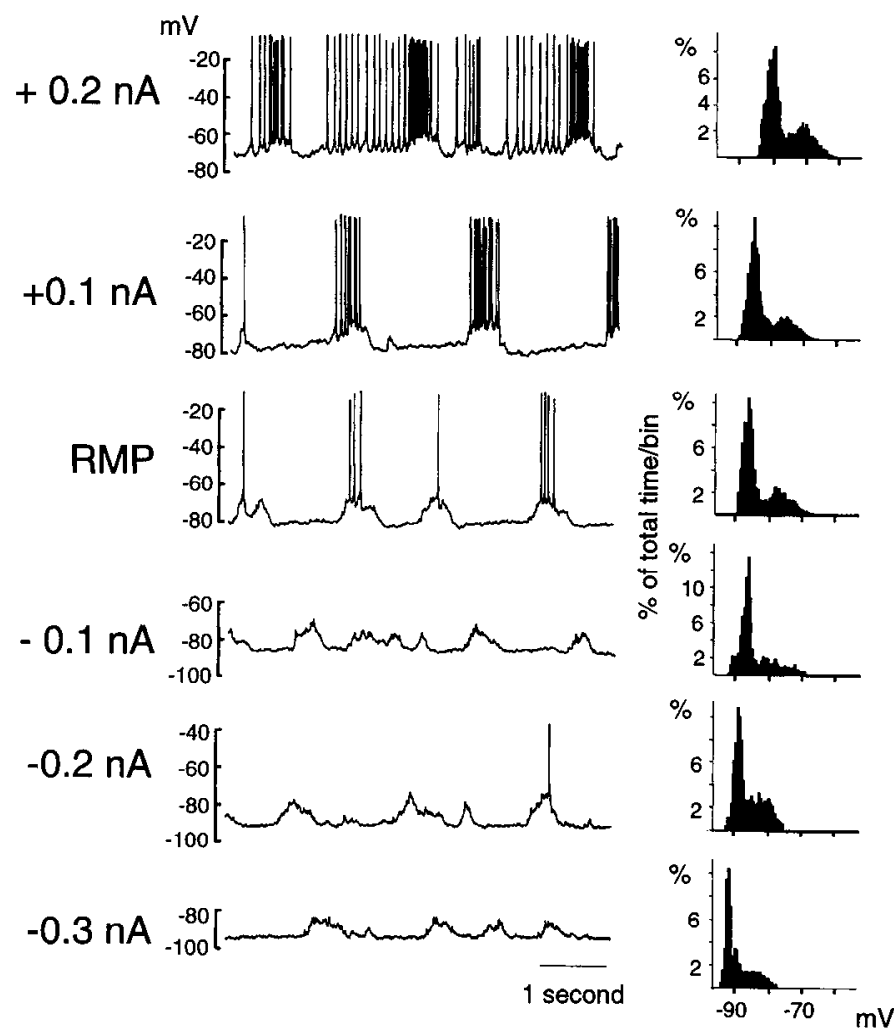

Figure 5. The amplitude and frequency of occurrence of the membrane potential transitions present in bistable cells are not dependent on the basal membrane potential of the accumbens neuron. Progressive depolarization (top two traces) or hyperpolarization (bottom three traces) from RMP (center trace) alter the spike discharge trequency of the cell without affecting the frequency of occurrence or the amplitude of the depolarizing plateau potentials that comprise the bistable state. A membrane potential frequency histogram (as described in Fig. 3) is shown and illustrates the typical bimodal distribution of the membrane potential transitions that occur in bistable cells (MP, $-90 \mathrm{mV}$ and -72 $\mathrm{mV}$ ).

Fig. 4). The depolarized (excitable) periods lasted for an average of $419 \pm 209 \mathrm{msec}(150-1000 \mathrm{msec}, n=24)$ and occurred at a frequency of $0.8 \pm 0.5 \mathrm{~Hz}(0.1-2 \mathrm{~Hz}, n=24)$. On average, the bistable cells remained in the depolarized state for $31 \% \pm$ $20 \%$ of the recording period (range, $5 \%-84 \%, n=24$ ). Depolarizing or hyperpolarizing the membrane of the recorded cell by intracellular current injection did not modify the duration, frequency or amplitude of these events (Fig. 5), but instead only affected the frequency of spiking produced during the depolarized state.

In addition to the inactive state and the bistable activity state, 15 of 51 neurons recorded exhibited intermittent subthreshold oscillations of their membrane potentials that occurred at a frequency of $5-8 \mathrm{~Hz}$. These oscillations were observed as depolarizing deflections above the baseline membrane potential; however, hyperpolarization of the membranc typically shifted the polarity of the oscillations to a hyperpolarizing direction (Fig. $3 G)$.

Responses evoked in accumbens neurons by stimulation of afferent fibers from the amygdala, prefrontal cortex, and hippocampus

Prefrontal cortex stimulation. Stimulation of the prelimbic or infralimbic regions of the prefrontal cortex induced EPSPs in all 
Table 1. Evoked EPSPs and their convergence in single accumbens cells recorded in control and sham-lesioned animals

\begin{tabular}{|c|c|c|c|c|c|c|c|}
\hline $\begin{array}{l}\text { Stimu- } \\
\text { lation } \\
\text { site }\end{array}$ & $\begin{array}{l}\text { Number } \\
\text { cells } \\
\text { respond- } \\
\text { ing }\end{array}$ & Latency & Amplitude ${ }^{n}$ & Duration & Time to peak & $\begin{array}{l}\text { Rise time } \\
d V / d t\end{array}$ & Convergence \\
\hline Cortex & $25 / 26$ & $\begin{array}{l}5.3 \pm 2.6 \mathrm{msec} \\
(1.6-12 \mathrm{msec})\end{array}$ & $\begin{array}{l}14.1 \pm 8.1 \mathrm{mV} \\
(5-35 \mathrm{mV})\end{array}$ & $\begin{array}{l}48.9 \pm 25.3 \mathrm{msec} \\
(18-120 \mathrm{msec})\end{array}$ & $\begin{array}{l}7.9 \pm 4.1 \mathrm{msec} \\
(2.7-19 \mathrm{msec})\end{array}$ & $\begin{array}{l}1.9 \pm 1.3 \mathrm{mV} / \mathrm{msec} \\
(0.4-4.5 \mathrm{mV} / \mathrm{msec})\end{array}$ & $\begin{array}{l}\text { Fornix, 19/20 } \\
\text { Amygdala, } 7 / 7 \\
\text { Both, 6/7 }\end{array}$ \\
\hline Amygdala & $7 / 7$ & $\begin{array}{l}17.1 \pm 5.4 \mathrm{msec} \\
(10-25 \mathrm{msec})\end{array}$ & $\begin{array}{l}15.3 \pm 11.7 \mathrm{mV} \\
(7-40 \mathrm{mV})\end{array}$ & $\begin{array}{l}79.2 \pm 30 \mathrm{msec} \\
(40-120 \mathrm{msec})\end{array}$ & $\begin{array}{l}12.6 \pm 6.2 \mathrm{msec} \\
(6-18.5 \mathrm{msec})\end{array}$ & $\begin{array}{l}1.4 \pm 0.9 \mathrm{mV} / \mathrm{msec} \\
(0.5-3.1 \mathrm{mV} / \mathrm{msec})\end{array}$ & $\begin{array}{l}\text { Cortex, } 7 / 7 \\
\text { Fornix, } 6 / 7 \\
\text { Both, } 6 / 7\end{array}$ \\
\hline Fornix & $19 / 21$ & $\begin{array}{l}7.8 \pm 4.6 \mathrm{msec} \\
(2.5-20 \mathrm{msec})\end{array}$ & $\begin{array}{l}13.5 \pm 9.7 \mathrm{mV} \\
(5-36 \mathrm{mV})\end{array}$ & $\begin{array}{l}71.2 \pm 43 \mathrm{msec} \\
(20-180 \mathrm{msec})\end{array}$ & $\begin{array}{r}9.7 \pm 3.9 \mathrm{msec} \\
(3.2-19.4 \mathrm{msec})\end{array}$ & $\begin{array}{l}2.0 \pm 1.9 \mathrm{mV} / \mathrm{msec} \\
(0.1-4.4 \mathrm{mV} / \mathrm{msec})\end{array}$ & $\begin{array}{l}\text { Cortex, } 19 / 19 \\
\text { Amygdala, } 7 / 7 \\
\text { Both, } 6 / 6\end{array}$ \\
\hline
\end{tabular}

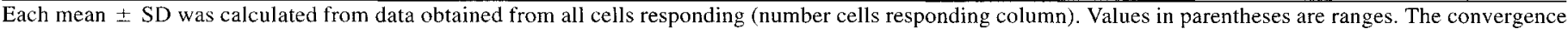
column shown number of cells responding to one or more additional stimulation sites.

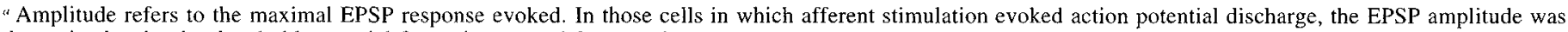
determined to be the threshold potential for action potential generation.

but one of the neurons tested (i.e., 19 of 20 cells in control animals; Table 1). In approximately half of the cells tested ( 9 of 19 ), the evoked excitatory potentials were followed by IPSPS (Fig. $6 \mathrm{~A}$; average amplitude, $-9.2 \pm 5.0 \mathrm{mV}$; latency, $31.2 \pm$ $14 \mathrm{msec}$; duration measured from response onset to return to baseline, $69.6 \pm 63.6 \mathrm{msec}$ ). Furthermore, only 4 of 19 cells exhibited a late EPSP (12-25 $\mathrm{mV}$ in amplitude; $40-55 \mathrm{msec}$ duration) which occurred at a latency of $45-80 \mathrm{msec}$ (Fig. 6B). Stimulation of the PFC evoked an EPSP that was of sufficient amplitude to trigger spike discharge in $47 \%$ (9 of 19) of these

\section{A}

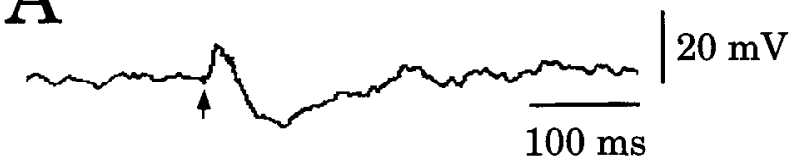

B

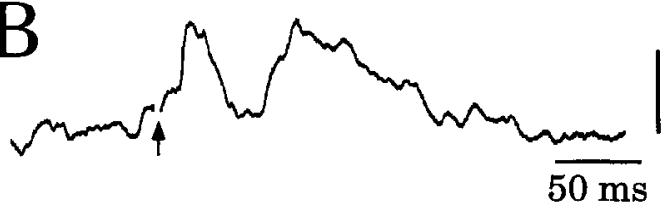

$\mathrm{C}$

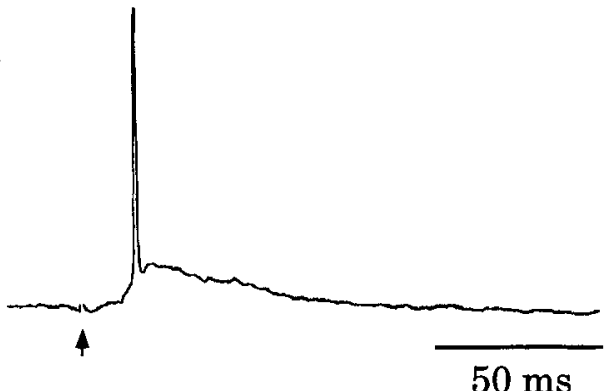

$20 \mathrm{mV}$
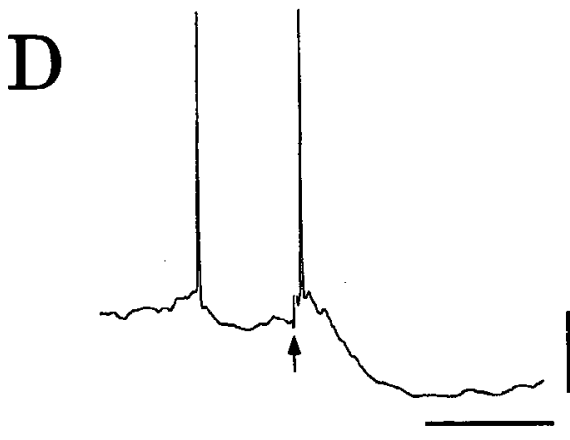

$50 \mathrm{~ms}$
$20 \mathrm{mV}$
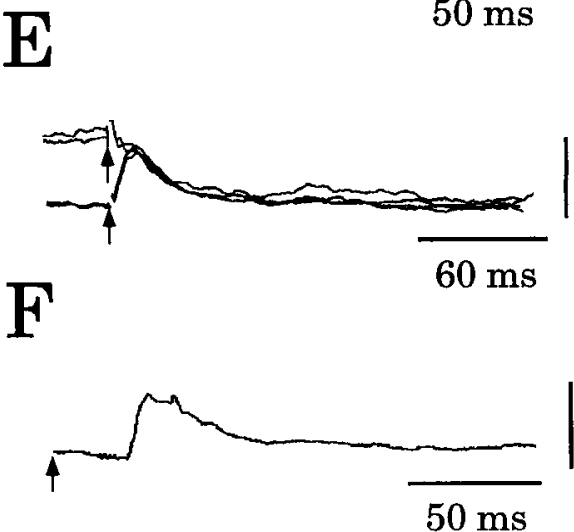

$20 \mathrm{mV}$

$20 \mathrm{mV}$

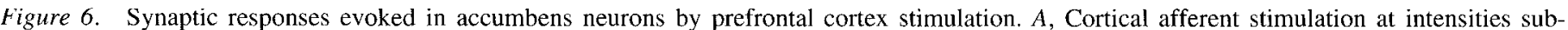

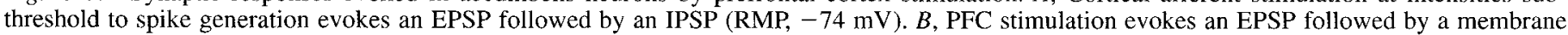

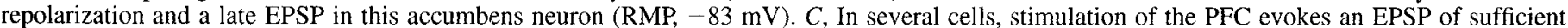
amplitude to trigger action potential discharge (RMP, $-62 \mathrm{mV}$ ).

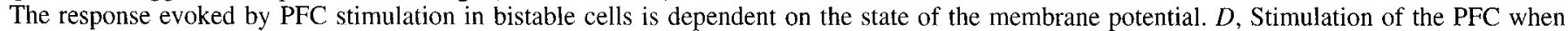

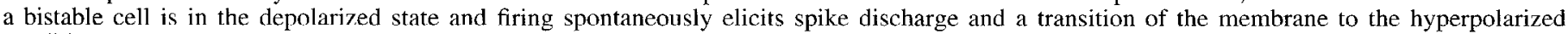

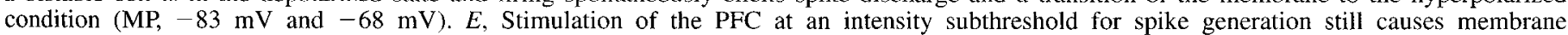

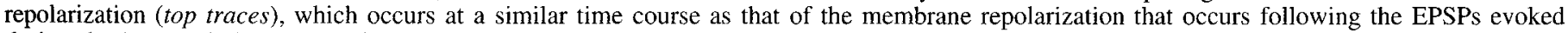

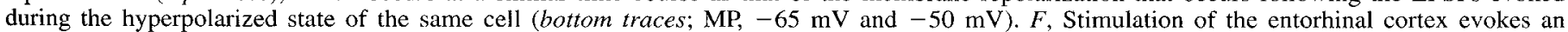

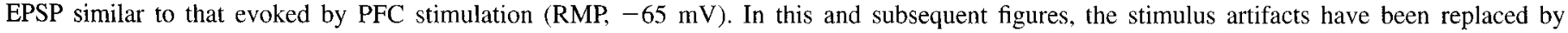
arrows. 

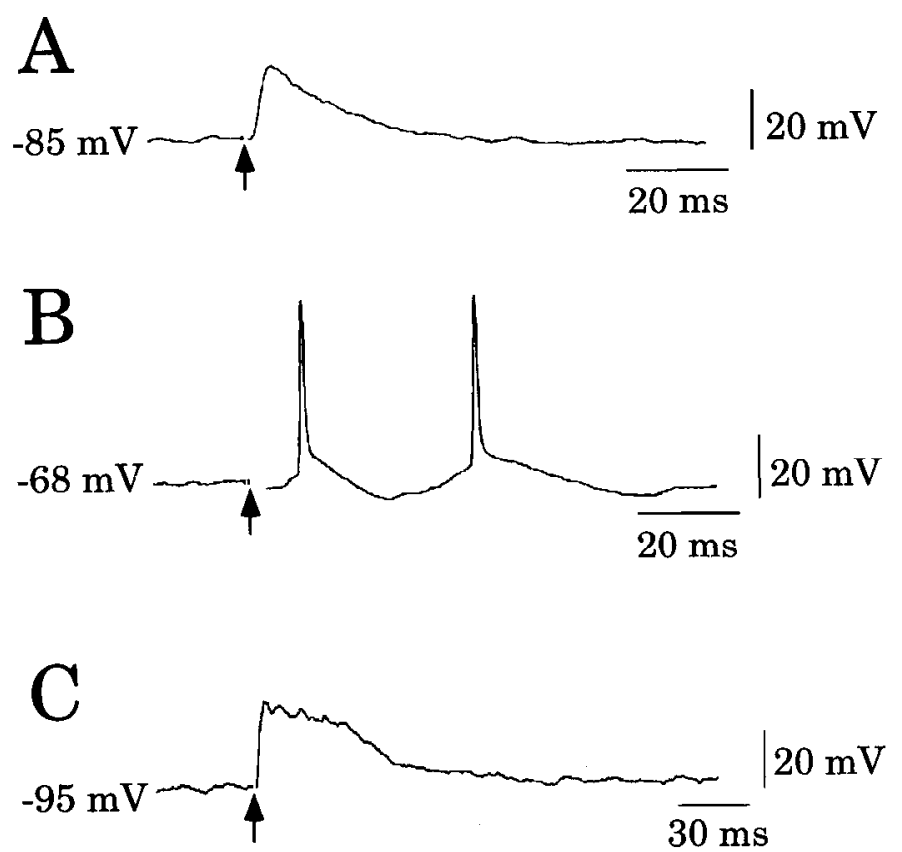

Figure 7. Synaptic responses evoked in accumbens neurons hy fornix stimulation. Stimulation of the fornix evokes EPSPs and extended depolarizing events in accumbens neurons. $A$, In response to fornix stimulation (arrow), this nonfiring accumbens cell exhibits a large amplitude EPSP (RMP, $-85 \mathrm{mV}$ ). $B$, In a bistable neuron, stimulation of the fornix during the depolarized state evoked an EPSP that was also followed by an IPSP-EPSP sequence. Action potentials were triggered by both EPSPs (RPM, $-68 \mathrm{mV}$ ). $C$, In contrast, stimulation of the fornix during recordings from a bistable neuron during its hyperpolarized state evokes a long-lasting EPSP (MP, $-95 \mathrm{mV}$ at the hyperpolarized state).

neurons (Fig. $6 C$ ). In bistable cells, PFC stimulation was more likely to trigger spike discharge when the cell was in the depolarized state. The evoked response was then followed by a rapid switch to the hyperpolarized state in every case examined $(n=7$; Fig. $6 D)$. Furthermore, this transition occurred in every case examined independent of whether the stimulation had evoked spike discharge (Fig. 6E). In contrast, when the membranes of bistable cells were in the hyperpolarized state (i.e., range, -95 to $-65 \mathrm{mV}$ ), stimulation of the PFC stimulation evoked large amplitude EPSPs (Fig. $6 E$ ) but failed to trigger spike discharge in $90 \%$ ( 9 of 10 ) of the cases. Stimulation of the entorhinal cortex evoked a similar pattern of response in five of six accumbens cells recorded (Fig. $6 F$ ).

Only one neuron did not respond to PFC stimulation with an EPSP, but instead exhibited an evoked IPSP. However, increasing the stimulus amplitude induced a decrease in the onset latency of the IPSP (i.e., from $3 \mathrm{msec}$ to $2.6 \mathrm{msec}$; not shown), which suggests that this response may be mediated polysynaptically.

Hippocampal afferent stimulation. Stimulation of the fornix also evoked EPSPs or an EPSP/IPSP sequence in 14 of 15 cells tested (Fig. $7 A, B$, Table 1), although action potential discharge could be evoked in only three of those cells. In 9 of 12 bistable cells, fornix stimulation evoked a plateau-like response during which the membrane potential of the cell depolarized to approximately the same level as that observed when these bistable cells are in their depolarized state. These responses consisted of either (1) an EPSP that had a prolonged plateau component lasting 46$60 \mathrm{msec}$ before repolarization of the membrane occurred $(n=$ 2; Fig. $7 C$ ), or (2) a maintained switch to the depolarized state
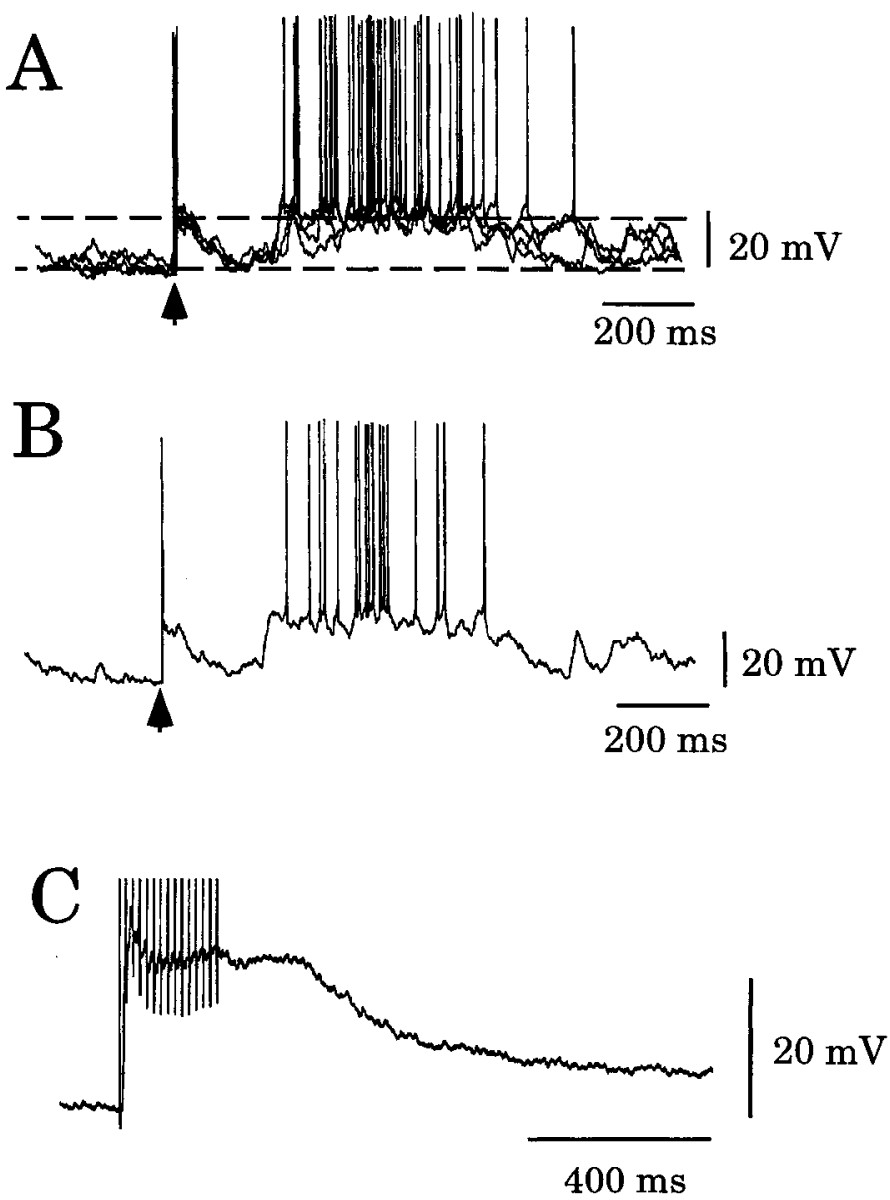

Figure 8. A condition resembling the depolarized state of a bistable neuron can be evoked by fornix stimulation. $A$, In a recording made from an accumbens bistable cell when it is in the hyperpolarized state, stimulation of the fornix (arrow, four traces overlaid) evokes a fast EPSP followed by a partial repolarization of the membrane which is followed by a switch to the depolarized state. $B$, In a display of one of the tracings shown in $A$, the prestimulus membrane potential is similar to the membrane potential of the cell when it is in the hyperpolarized state (bottom dashed line, MP, $-95 \mathrm{mV}$ ), whereas the evoked plateau depolarization reaches membrane potentials that are equivalent to those observed during the depolarized state of this neuron (upper dashed lines, MP, $-75 \mathrm{mV}$ ). $C$, When the fornix is activated by a brief train of stimuli $(5-15$ pulses at $30-50 \mathrm{~Hz})$, a bistable cell in the hyperpolarized state exhibits a prolonged large amplitude depolarization of the membrane that is maintained for $200 \mathrm{msec}$ following the last stimulus before returning to baseline membrane potential (MP, $-90 \mathrm{mV}$ and -72 $\mathrm{mV}$ ). The stimulation events are shown by their stimulus artifacts that were retained in this example.

$(n=7)$. Thus, when the bistable cells were in their depolarized phase, stimulation of the fornix evoked only a small amplitude EPSP (approximately $1-9 \mathrm{mV}$ ). However, when the cells were in their hyperpolarized state, fornix stimulation evoked an EPSP followed by a longer latency $(92-220 \mathrm{msec})$ switch to the depolarized state $(n=7$; Fig. $8 A, B)$. Furthermore, stimulation of the fornix with a train of pulses $(20-75 \mathrm{~Hz}, 200-300 \mathrm{msec}$ duration, $n=4$ ) induced a sustained depolarization of the membrane that lasted for approximately $200 \mathrm{msec}$ beyond the termination of the stimulus train (Figs. $8 C, 9 A$ ). This depolarized plateau was similar in amplitude and duration to the spontaneously occurring depolarizing shifts observed in bistable cells. In addition, stimulation of the PFC at intensities that were subthreshold for evoking spikes when the cell was in the hyper- 


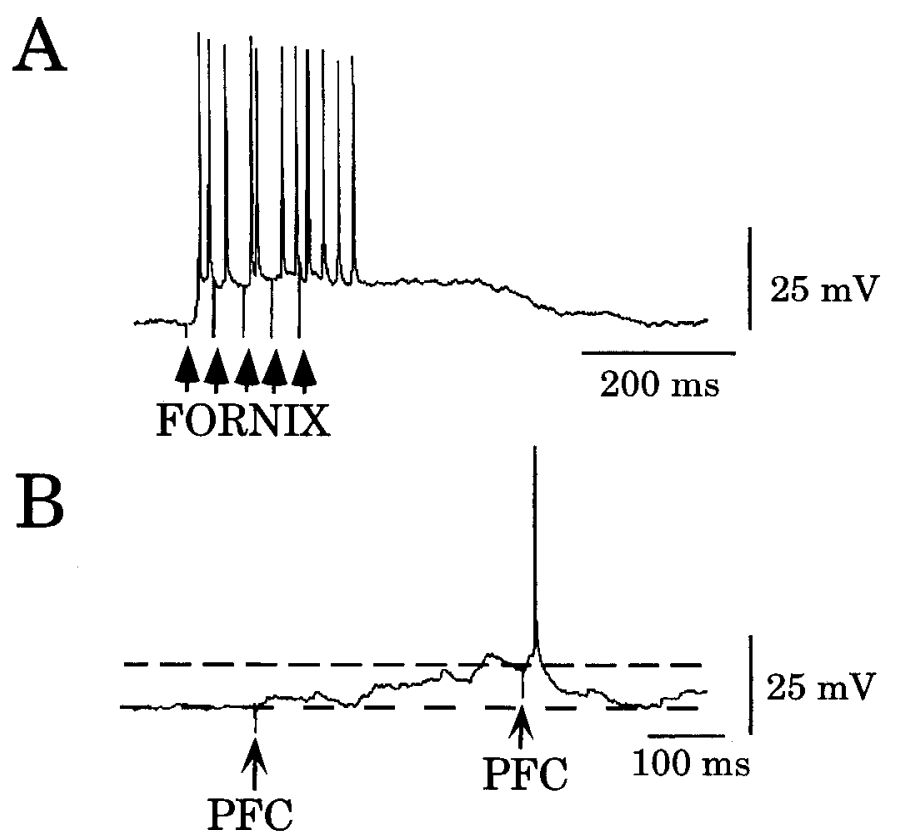

C

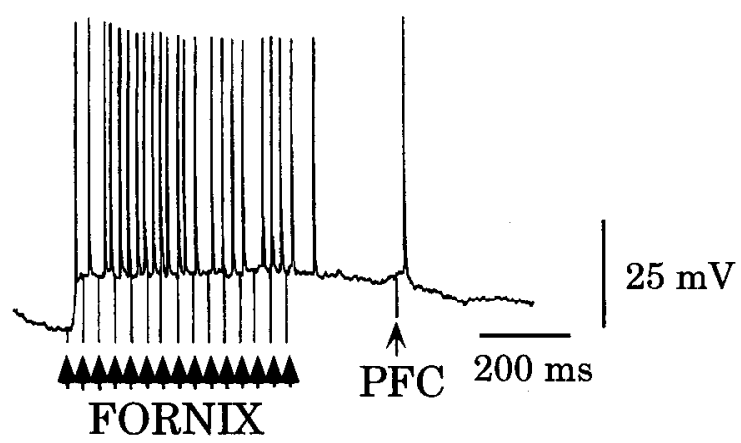

Figure 9. The synaptic responses evoked in accumbens neurons by PFC stimulation are facilitated when preceded by a fornix stimulationinduced depolarized state. $A$, Stimulation of the fornix with a train of pulses (stimulus artifacts retained) induces a long-lasting depolarization of the accumbens cell membrane that resembles the depolarized membrane potential state of a bistable cell. $B$. In the same cell, stimulation of the PFC when the cell is in the hyperpolarized state fails to evoke an action potential ( first arrow). However, when the cell shows a spontaneous transition to the depolarized state, the same amplitude of PFC stimulation (second arrow) evokes an action potential. $C$, Stimulation of the fornix with trains evokes a prolonged transition of the membrane to the depolarized state. During this depolarization, stimulation of the PFC at an intensity that was subthreshold for spike triggering in the hyperpolarized state (i.e., at the same amplitude used in $B$ ) readily evokes a spike. The stimulus intensity and evoked spike latency were identical to that in $B$ (RMP, $-79 \mathrm{mV}$ and $-69 \mathrm{mV}$ ).

polarized phase readily evoked spike discharge during the trainevoked depolarizing plateau ( $n=4$; Fig. 9). The time course of this enhancement of cortical input appears therefore to depend on the duration of the fornix stimulation-induced depolarizing plateau.

Only one cell tested exhibited an IPSP, but not an EPSP, in response to fornix stimulation. Furthermore, this was the same cell that also responded to PFC stimulation with an evoked IPSP.

Amygdala stimulation. Stimulation of the basolateral nucleus of the amygdala induced long-latency (10-25 msec) EPSPs in every accumbens neuron tested ( $n=7$; Fig. $10 \mathrm{~A}$, Table 1 ), although in most cases the stimulus failed to evoke action potential
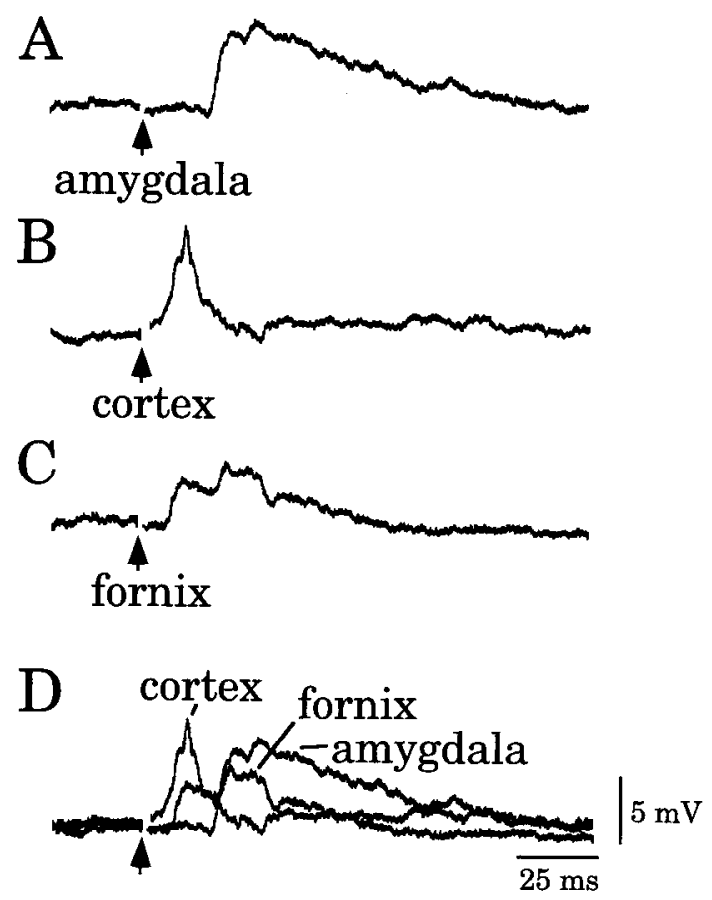

Figure 10. Accumbens neurons typically exhibited evoked responses to stimulation of each of the afferent sites examined. $A$, Stimulation of the BL nucleus of the amygdala evoked an EPSP that exhibited a long onset latency. $B$, The same accumbens cell also responded to PFC stimulation with a short-latency EPSP. $C$, Stimulation of the fornix also evoked a short-latency EPSP in this same cell. $D$, Overlay of the three responses (RMP, $-77 \mathrm{mV}$ ).

discharge (evoked spikes, two of seven cells). In contrast, stimulation of the nearby zona incerta region failed to evoke a measurable response $(n=3)$. Unlike stimulation of the PFC, the responses evoked in bistable cells by amygdala stimulation were not altered by the depolarized or hyperpolarized states of the membrane, nor were they affected during fornix stimulationinduced membrane depolarizations $(n=6)$. Amygdala-evoked responses also exhibited a high degree of convergence with the other sites. Thus, in every case examined, cells that responded to hippocampal stimulation also responded to PFC stimulation and vice versa $(n=14)$. In addition, six of seven cells tested for convergence of evoked responses from the PFC, fornix, and the amygdala exhibited responses to all three stimulation sites (Fig. 10A-D, Table 1).

All three inputs were studied using a wide range of stimulus intensities (0.1-1.5 mA). In every case in which stimulation of the PFC, the amygdala, or the fornix was tested, the responses exhibited increased amplitudes but constant onset latencies with increasing stimulus intensities (Fig. 11). These characteristics are often taken as evidence for a monosynaptic response (Sugimori et al., 1978). Nonetheless, the very long latency of the amygdala-evoked responses would be difficult to reconcile with a monosynaptic origin. In addition, the responses to fornix stimulation did on occasion exhibit multiple components (Fig. $10 C, D$ ), raising the possibility that a multisynaptic pathway may also play a role at least in the late components of this response.

\section{Effects of fimbria-fornix transection on the bistable activity pattern of nucleus accumbens neurons}

In order to test whether the hippocampal projection to the accumbens is involved in regulating the bistable state, the fimbria- 


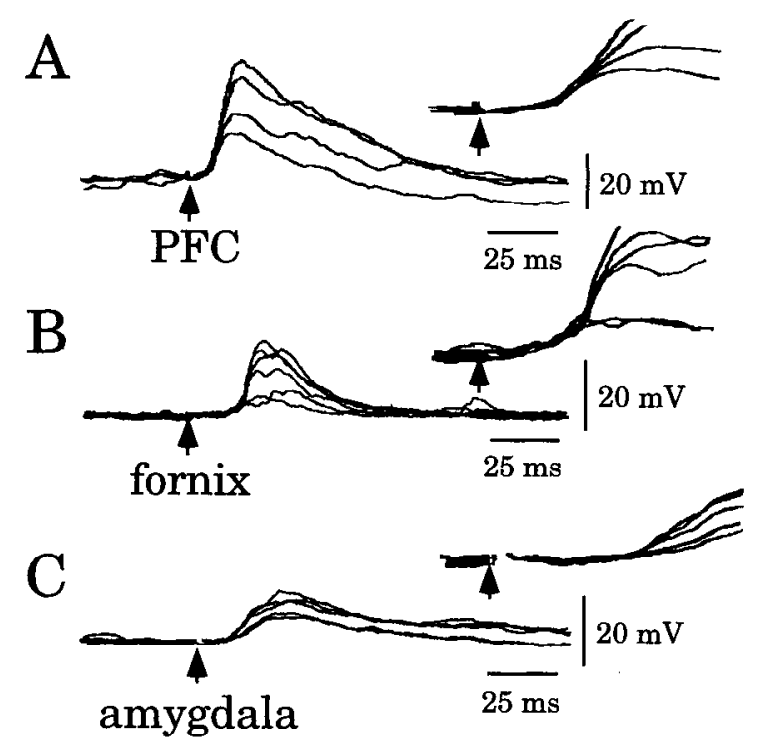

Figure 11. The responses of accumbens neurons to stimulation of the PFC and the fornix exhibit characteristics consistent with monosynaptic events. $A$, The responses to stimulation of the PFC with increasing stimulus amplitudes consist of single components that occur at a constant latency (MP, $-85 \mathrm{mV}$ and $-65 \mathrm{mV}$ ). $B$, The EPSPs evoked by stimulation of the fornix with increasing stimulus strength also occur at a constant latency to onset (RMP, $-66 \mathrm{mV}$ ). $C$, Stimulation of the BL nucleus of the anyggdala induces EPSPs with comparatively long onset latencies. Although the latency remains constant as the stimulus intensity is increased, the unusually long delay in the response onset suggests that multiple synaptic events may be involved in this response. Insets show the responses at a faster time base to allow for a more clear visualization of the constant onset latencies (MP, $-77 \mathrm{mV}$ and -55 $\mathrm{mV})$.

fornix was transected in a subset of animals approximately $1 \mathrm{hr}$ prior to the recording session. The data from these animals were included in the analysis only when subsequent histological analyses could verify that this pathway had been fully transected by an accurate placement of the knife cut, as described in the histology section (see below). In general, the physiological properties of accumbens neurons recorded in transected animals were not substantially different from those observed in intact animals, except as noted below.

In rats receiving a sham transection that failed to interrupt hippocampal afferents, the accumbens cells recorded exhibited similar properties as those in control animals, with the majority of the cells recorded (six of nine) exhibiting the bistable pattern of activity. Stimulation of the PFC in this group induced EPSPs in all neurons tested ( $n=6$; Table 2), and in four of six cases also evoked action potential discharge. Furthermore, as in control animals, stimulation of the PFC during the depolarized state of bistable cells evoked EPSPs or action potentials that were followed by a switch to the hyperpolarized state $(n=3)$, whereas stimulation of the fornix during the hyperpolarized state induced a switch to the depolarized state $(n=4)$. In addition, stimulation of the amygdala induced EPSPs in all six ncurons studied, and the degree of convergence between cortical, hippocampal, and amygdaloid afferents onto single cells (5 of 6) was within the range of that observed in intact animals.

In contrast, none of the accumbens neurons recorded from animals with histologically confirmed fornix transections were observed to fire spontaneously (intact, 32 of 42; transected, 0 of 9 ), and none of the cells exhibited bistable fluctuations in their membrane potential (intact, 24 of 42 ; transected, 0 of $9 ; p=$ 0.002 , Fisher exact test). The EPSPs evoked by cortical stimulation in the lesioned group were similar to those recorded in controls with respect to their onset latency (control, $5.3 \pm 2.6$ msec, 1.6-12 msec, $n=25$; transected, $3.8 \pm 1.6 \mathrm{msec}, 2-6$ msec, $n=5$; NS), amplitude (control, $14.1 \pm 8.1 \mathrm{mV}, 5-35$ $\mathrm{mV}, n=25 ;$ transected, $8.2 \pm 5.2 \mathrm{mV}, 3-10 \mathrm{mV}, n=5$; NS), and duration (control, $48.9 \pm 25.3 \mathrm{msec}, 18-120 \mathrm{msec}, n=25$; transected, $32.6 \pm 15.8 \mathrm{msec}, 20-60 \mathrm{msec}, n=5$; NS). In ad dition, although prefrontal cortical stimulation evoked EPSPs in all accumbens cells tested (Fig. 12A), the stimulus failed to evoke action potential discharge in any of the cells recorded in the transected rats ( $n=6$; Table 2 ). Furthermore, when the fornix was stimulated at a site between the location of the transection and the nucleus accumbens neurons recorded, EPSPs could be evoked in only one of six cells tested; this occurred even when the stimuli were delivered in trains (Fig. 12B). Stimulation of the amygdala yielded EPSPs in three of four neurons tested in transected rats (Fig. 12C), and these EPSPs were similar in amplitude and duration to those evoked by amygdala stimulation in control animals.

\section{Effects of lidocaine injected into the fornix on the bistable membrane potential}

In two animals a cannula was placed with its tip contacting the fimbria-fornix system to permit the injection of $1 \%$ lidocaine while recording from a cell in the accumbens. All four bistable cells tested were rendered silent within 1-3 min following the

Table 2. Effects of hippocampal afferent lesions on activity patterns and responses of nucleus accumbens neurons to cortical stimulation

\begin{tabular}{|c|c|c|c|c|c|}
\hline Condition & $\begin{array}{l}\text { \% Firing } \\
\text { spontaneously }\end{array}$ & $\%$ Bistable & $\begin{array}{l}\% \text { Showing } \\
\text { evoked EPSPs }\end{array}$ & EPSP amplitude & $\begin{array}{l}\text { \% Showing } \\
\text { evoked spikes }\end{array}$ \\
\hline Control & $\begin{array}{r}76.2 \% \\
(32 / 42)\end{array}$ & $\begin{array}{r}57.1 \% \\
(24 / 42)\end{array}$ & $\begin{array}{c}95 \% \\
(19 / 20)\end{array}$ & $\begin{array}{l}14.0 \pm 9.1 \mathrm{mV} \\
(5-35 \mathrm{mV})\end{array}$ & $\begin{array}{l}45 \% \\
(9 / 20)\end{array}$ \\
\hline Transected & $\begin{array}{c}0 \% \\
(0 / 9) \\
p<\mathbf{0 . 0 0 1}\end{array}$ & $\begin{array}{c}0 \% \\
(0 / 9) \\
p=\mathbf{0 . 0 0 2}\end{array}$ & $\begin{array}{c}83.3 \% \\
(5 / 6) \\
p=0.414\end{array}$ & $\begin{array}{l}8.2 \pm 5.2 \mathrm{mV} \\
(3-16 \mathrm{mV})\end{array}$ & $\begin{array}{c}0 \% \\
(0 / 6) \\
p=0.054\end{array}$ \\
\hline Sham & $\begin{array}{l}77.8 \% \\
(7 / 9) \\
p=0.647\end{array}$ & $\begin{array}{l}66.6 \% \\
(6 / 9) \\
p=0.444\end{array}$ & $\begin{array}{c}100 \% \\
(6 / 6) \\
p=0.770\end{array}$ & $\begin{array}{l}14.3 \pm 4.0 \mathrm{mV} \\
(10-20 \mathrm{mV})\end{array}$ & $\begin{array}{c}67 \% \\
(4 / 6) \\
p=0.323\end{array}$ \\
\hline
\end{tabular}

Numbers in parentheses are cells responsive/cells stimulated for each group and response type. $p$ values were obtained using the Fisher exact test. 
A

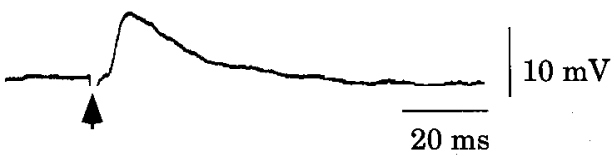

B

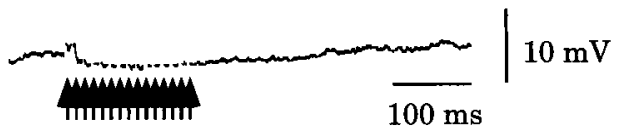

C

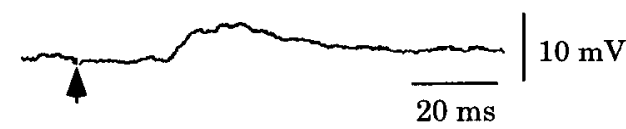

Figure 12. Transection of the fornix alters the response of accumbens neurons to PFC stimulation. $A$, In rats in which the fornix had been transected, stimulation of the PFC with the maximal stimulation current tested $(1.5 \mathrm{~mA})$ evoked an EPSP but could not evoke spike discharge in this accumbens neuron (RMP, $-81 \mathrm{mV}$ ). $B$, Delivering a train of pulses to the portion of the fornix proximal to the transection failed to evoke a response in this accumbens neuron (RMP, $-56 \mathrm{mV}$ ). $C$, Stimulation of the amygdala in a fornix-transected rat was still capable of evoking an EPSP (RMP, $-56 \mathrm{mV}$ ).

injection of lidocaine, with three of four cells no longer exhibiting the bistable membrane potential (Fig. 13). In those cells that were held for a sufficient period of time to allow for the lidocaine to wash out of the system (i.e., 15-20 min), there was a restoration of the bistable pattern of activity ( $n=2$; Fig. 13). In contrast, in two animals in which the cannula was placed in the dorsal septum, lidocaine injection failed to alter the bistable firing pattern on the three accumbens neurons tested. This effect of fornix inactivation appeared to be specific for bistable cell activity within the accumbens, since injection of lidocaine into the fornix failed to affect the membrane potential or firing pattern of six cells showing similar bistable activity states that were recorded from the orbital $\mathrm{PFC}$ immediately anterior to the rostral pole of the accumbens.

\section{Midline thalamic nuclei stimulation}

Since the sites of fornix stimulation and injection were located near the site at which the fornix passes in close proximity to the paraventricular (PV) thalamic nucleus, which also projects to the accumbens (Su and Bentivoglio, 1990), we studied whether the response to fornix stimulation may have involved this adjacent system as well. However, although stimulation of the PV thalamic nuclei did evoke EPSPs followed by long-lasting IPSPS (EPSP latency, 6 and $10 \mathrm{msec}$; duration, 18 and $65 \mathrm{msec}$; amplitude, 11 and $22 \mathrm{mV}$ ) in two of four cells recorded in the accumbens, none of the bistable cells recorded exhibited a transition to the depolarized level $(n=2)$.

\section{Histology}

The tracks made by the recording electrodes were localized within accumbens tissue following fixation and histological processing as described in Materials and Methods. Only data collected from cells that had been recorded from electrode tracks that penetrated the boundaries of the nucleus accumbens were analyzed further. In order to optimize the accuracy of electrode track identification, a maximum of four electrode penetrations into the accumbens was attempted in each animal. The location

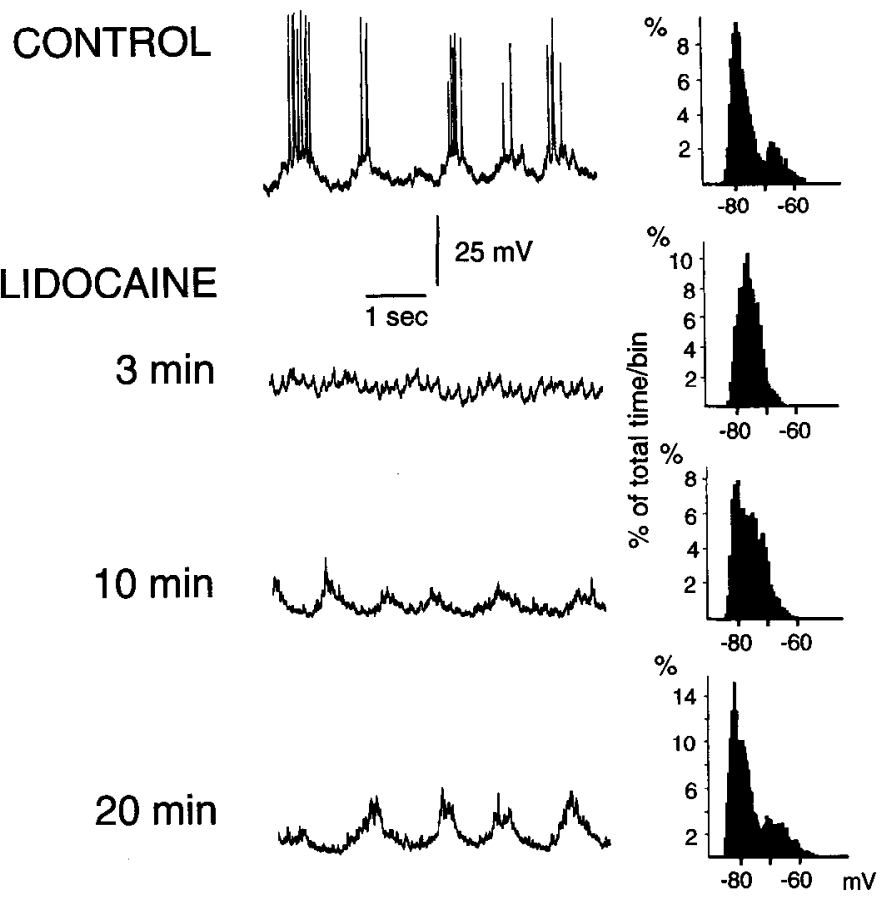

Figure 13. The injection of lidocaine into the fornix induces a temporary suppression of the membrane potential transitions in bistable neurons. Traces from a bistable cell before (control) and after lidocaine injection, as recorded 3, 10, and 20 min after the injection. Although a $6 \mathrm{~Hz}$ oscillation in the membrane potential is evident, the cell stopped firing action potentials and no transitions to the depolarized state were observed. Ten minutes after the injection, depolarizations resembling the spontaneous shifts in membrane potential are again present. Twenty minutes after injections, the return to the bistable pattern is evident, although the cell is still firing slower than in the predrug condition. At the right of each trace a membrane potential frequency histogram reveals the characteristic bimodal distribution and its elimination following xylocaine injection. By $20 \mathrm{~min}$ postinjection, there is a partial recovery of the initial bimodal distribution in membrane potential (MP, $-79 \mathrm{mV}$ and $-66 \mathrm{mV}$ ).

of the stimulation sites was also verified by localizing the tip of the track produced by the stimulating electrode.

In one set of experiments, the fornix was transected at least $1 \mathrm{hr}$ prior to starting the recording session. Data was included in the transection group only when subsequent histological examination confirmed that a complete section of the fornix had been made (Fig. 14A). In a separate group of experiments, the effects of knife cuts that interrupted nearby fiber pathways but spared the fornix were examined (Fig. 14B). In these rats, microscopic examination confirmed that the fornix had been spared, although in one of the animals there was some additional damage to the dorsal septum. The results obtained from this rat were not noticeably different from those acquired in intact rats.

\section{Discussion}

Many of the basic membrane properties and evoked responses of nucleus accumbens neurons recorded in vivo were similar to those observed in vitro (Uchimura et al., 1989a,b; Pennartz et al., 1992a; O'Donnell and Grace, 1993b), except that the neurons recorded in the intact preparation were under the continuous influence of spontaneous synaptic potentials. Thus, unlike the brain slice preparation, the activity of the neurons recorded in vivo is driven by their afferent input. This input appears to subserve several functions that differentiate basal activity in the 

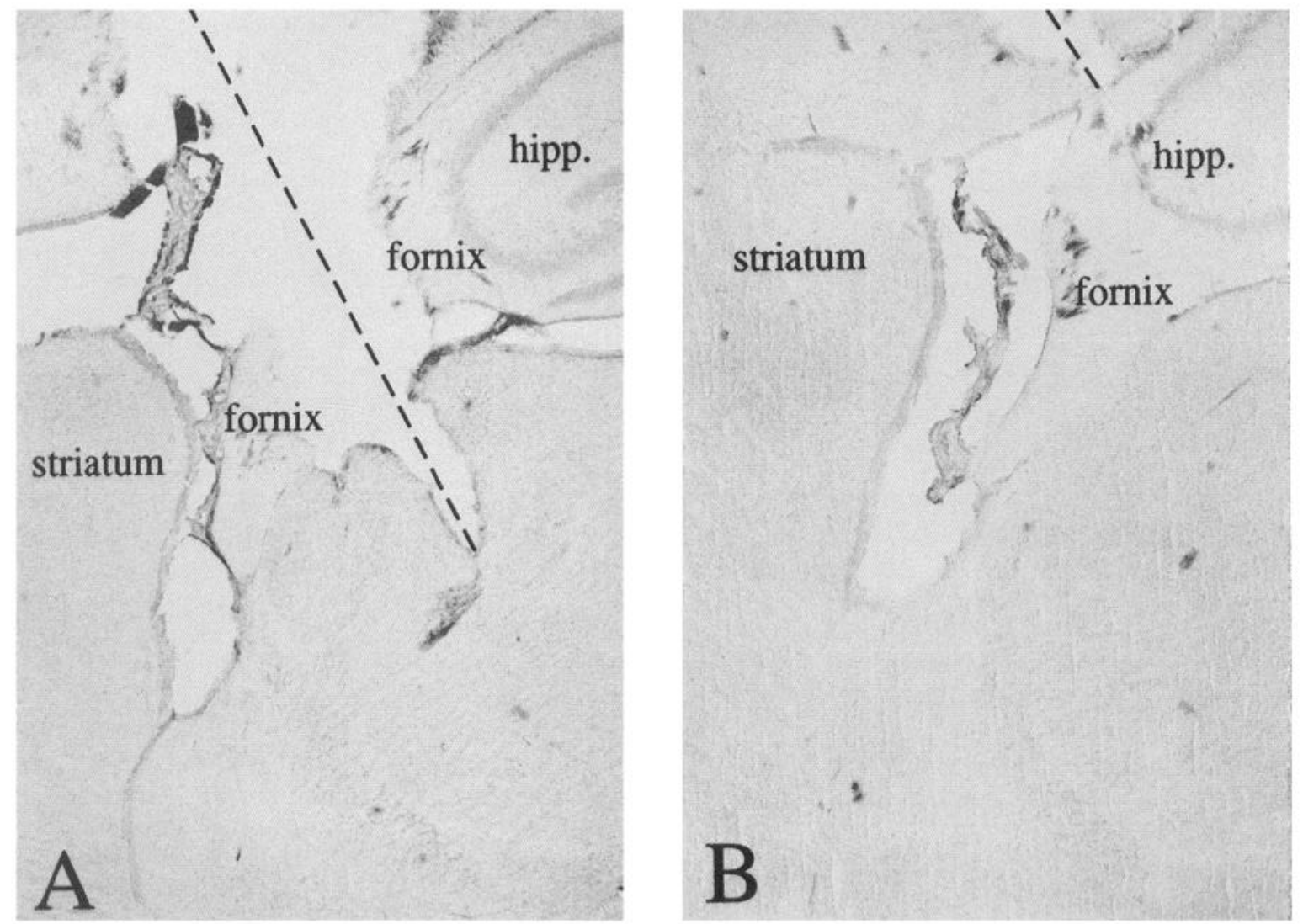

Figure 14. Photomicrographs of $70 \mu \mathrm{m}$ thick sagittal brain slices obtained from a transected and a sham-lesioned rat. A, Full transection of the fornix (dashed line). B, A more superficial penetration of the knife (dashed line) that spared the fornix.

intact preparation, such as driving spontaneous spike firing, determining the state of the bistable membrane potential, augmenting the impact of low threshold spikes, and subserving a primary role in the generation of rhythmic oscillations. To investigate the degree of convergence and interaction among afferents arising from widely dispersed brain nuclei (i.e., PFC, amygdala, and hippocampus) onto single accumbens neurons, and in particular to facilitate the assessment of the functional impact of these afferents on accumbens cell activity states, it was necessary to use the in vivo preparation.

\section{Intrinsic membrane properties}

Most of the basic physiological properties of accumbens neurons recorded in vivo were analogous to those reported using in vitro preparations. The membrane potential of these cells was within the range of those reported in vitro (Uchimura et al., 1986, 1989a,b; Pennartz et al., 1991, 1992a,b, 1993; Uchimura and North, 1991; O'Donnell and Grace, 1993b, 1994a). Cells recorded in both preparations exhibited a slow depolarization preceding spike discharge that corresponds to the increase in the slope of the $I-V$ plot at depolarized membrane potentials (O'Donnell and Grace, 1993b). As determined in the more accessible in vitro preparation, this depolarization was shown to be mediated by a $\mathrm{Ca}^{2+}$-dependent conductance (O'Donnell and Grace, 1993b). Membrane hyperpolarization reveals an inward rectification in both preparations when the amplitude of current injected was greater than $-0.5 \mathrm{nA}$ (Uchimura et al., 1989a). Furthermore, accumbens cells in both preparations (O'Donnell and Grace, 1993b) exhibit slow, all-or-none depolarizations that resemble the low threshold spikes (LTS) described in other systems (Jahnsen and Llinás, 1984). The LTS probably underlies the rebound spike firing observed following hyperpolarizing pulses, and is likely to contribute to bursts of action potentials occurring during the peak of spontaneous membrane potential depolarizations observed in vivo. A similar pattern of activity has been described for medium spiny neurons in the caudateputamen recorded in vivo (Wilson and Groves, 1981; Calabresi et al., 1990; Wilson, 1993; Onn et al., 1994), and recordings performed in behaving animals showed that these dorsal striatal cells also fire spikes in bursts (Aldridge and Gilman, 1991).

Approximately $30 \%$ of the cells showed spontaneous $5-8 \mathrm{~Hz}$ oscillations in their membrane potential. However, these oscillations were not continuously present; instead, the cells were observed to spontaneously enter and exit the oscillatory mode in an irregular manner. Spontaneous oscillating activity that occurs at different frequencies has been described in other cell types as well, such as the slower $(2-4 \mathrm{~Hz})$ oscillations that are produced in thalamic neurons by the alternation of the LTS with a $\mathrm{Ca}^{2+}$-dependent membrane afterhyperpolarization (AHP) (Steriade and Llinás, 1988; McCormick and Pape, 1990; Amzica et al., 1992). However, two pieces of evidence suggest that, unlike the thalamic neurons, the oscillations in the accumbens cell membrane potential are not endogenously generated: (1) in vitro intracellular recordings show that, unlike the thalamic neurons, the LTS and AHP in accumbens cells are not of sufficient amplitude to drive sustained oscillatory activity (O'Donnell and Grace, 1993b), and (2) in most of the cells displaying the 5-8 
Hz oscillation, a prominent LTS could not be evoked by current injection. Thus, given the absence of membrane properties capable of supporting spontaneous oscillatory spike firing combined with the absence of sustained oscillatory activity in the in vitro preparation, it is likely that the membrane potential oscillations occurring in the accumbens cells in vivo are mediated via afferent inputs.

\section{Bistable membrane potential}

More than half of the cells recorded in the accumbens exhibited rapid transitions between two distinct steady-state membrane potentials, with the two membrane potentials separated by approximately $15 \mathrm{mV}$. The membrane potentials present during the depolarized state of bistable cells are within the range of those occurring in spontaneously discharging accumbens cells (i.e., tonically active, $-63.8 \pm 6.7 \mathrm{mV}$ vs depolarized state, -63.2 $\pm 7.4 \mathrm{mV}$ ). On the other hand, the membrane potentials of bistable cells at their hyperpolarized state are not as hyperpolarized as the nonfiring accumbens cells (i.e., non-firing, -87.1 $\pm 6.7 \mathrm{mV}$ vs hyperpolarized state, $-77.3 \pm 7.1 \mathrm{mV}$ ). Thus, although it is possible that the afferent inputs and membrane properties may cause cells to be in either a hyperpolarized, nonfiring state or in a depolarized, tonically active condition, the very polarized membrane potential of nonfiring cells is probably due to more than just the absence of hippocampal input onto those cells.

One factor that appeared to influence the bistable state was the level of anesthesia in that during initial experiments it was found that injection of supplemental anesthetic doses in bolus form caused a substantial diminution of the number of transitions to the depolarized state. Since we required a stable level of the bistable pattern to allow quantitative comparisons of lesion- or drug-induced changes, we employed a microdrip continuous infusion system that would assure a steady-state level of anesthesia throughout the experiment.

The origin of the bistable membrane potential observed in nucleus accumbens neurons (Yim and Mogenson, 1988; Leung and Yim, 1993) and in subpopulations of striatal cells recorded in vivo (Hull et al., 1970; Wilson and Groves, 1981; Calabresi et al., 1990; Wilson, 1992a,b, 1993) is not clear, although several possible mechanisms have been advanced by others, including (1) the (in)activation of a $\mathrm{K}^{+}$conductance (Wilson, 1992b), (2) the activation of receptors for ACh or DA (Kitai and Surmeier, 1993), or (3) continuous afferent drive by corticostriatal cells (Wilson, 1993; Cowan and Wilson, 1994). In the dorsal striatum, activation of $\mathrm{ACh}$ receptors at hyperpolarized membrane potentials triggers the opening of A-type potassium conductances $\left(I_{A}\right)$, which are believed to suppress excitatory inputs and thereby slow the firing rate of the cell. On the other hand, at depolarized membrane potentials, activation of $I_{A}$ is proposed to cause an increase in membrane excitability. In this model, $\mathrm{ACh}$ is proposed to act as a state stabilizer (Kitai and Surmeier, 1993). Conversely, our data is not consistent with models in which intrinsic properties of accumbens cells or tonic influences of neuromodulators are the primary determinant of these fluctuations in membrane potential. Thus, although changing the membrane potential is known to activate or inactivate most of the ionic conductances that may be involved in endogenously driven oscillatory activity (Llinás and Yarom, 1981; Jahnsen and Llinas, 1984; Stafstrom et al., 1984; Llinás, 1988), direct polarization of accumbens cell membranes failed to affect the frequency and amplitude of the membrane potential changes that underlie these events. Therefore, our results suggest that the bistable state in nucleus accumbens cells in vivo is not determined by intrinsic membrane properties, but instead is driven by afferent processes, with the data strongly implicating the hippocampal afferents in this process.

\section{Convergence of synaptic responses onto accumbens neurons}

Membrane depolarization and spike activity in accumbens ncurons could be evoked to varying degrees by stimulating each of the three primary excitatory afferents to this region: the hippocampal fibers within the fornix (Kelley and Domesick, 1982; De France et al., 1985), the PFC (Fuller et al., 1987), and the amygdala-accumbens path (Callaway et al., 1991). In this study, every accumbens neuron tested exhibited some level of synaptic activation in response to stimulation of one or more of these afferent systems. Stimulation of either the entorhinal cortex or the infralimbic or prelimbic regions of the prefrontal cortex resulted in an EPSP in 19 of 20 cells (95\%), which in $47 \%$ (9 of 19) of the cells triggered an action potential. The evoked EPSPs were usually followed by IPSPs, probably due to activation of GABAergic collaterals arising from neighboring accumbens neurons (Calabresi et al., 1991; Nisenbaum and Berger, 1992; O'Donnell and Grace, 1993b) that also were activated by the afferent stimulation. The only neuron that responded with an IPSP exhibited this response to stimulation of all three inputs (i.e., PFC, hippocampus, and amygdala); furthermore, the variable latency in the IPSP onset suggests that it was mediated polysynaptically, possibly as a result of preferential activation of neighboring GABAergic cells. Stimulation of the fornix, which carries inputs from the subiculum (Swanson and Cowan, 1975; Kelley and Domesick, 1982), also induced EPSPs in 93\% of the cases (19 of 21), although action potentials were evoked in only $24 \%$ ( 5 of 21 ) of the cells tested. These responses were usually followed by an IPSP and occasionally by a late depolarization. Stimulation of the basolateral nucleus of the amygdala also caused long-latency EPSPs in seven of seven cells, but only evoked spike discharge in $29 \%$ ( 2 of 7 ) of the cells tested. Thus, although EPSPs were evoked in accumbens cells from each stimulation site in a high percentage of cases, these stimuli typically were not capable of evoking spike discharge, suggesting that activation of several convergent inputs may be required to trigger spike firing in these cells. Therefore, the high degree of convergence of excitatory inputs may be a necessary prerequisite for the transfer of information through the accumbens, given that the level of convergence of two or three inputs onto a single neuron approached $100 \%$ in this study.

The high degree of synaptic convergence observed in these studies is consistent with anatomical studies showing an extensive overlap of afferent inputs from different cortical regions within the nucleus accumbens (Domesick, 1981). On the other hand, others using electrophysiological measures have reported a low degree of convergence of amygdala and hippocampal inputs onto nucleus accumbens neurons (Callaway et al., 1991). However, this discrepancy can probably be attributed to the use of extracellular recording techniques, which must relay on evoked spike discharge to assess connectivity. Given the fact that our study found a high degree of convergence with respect to evoked EPSPs but a low probability of evoking a spike, it is likely that most of the convergence was missed by relying on spike discharge as an indicator of convergence. Another concern is the possibility that at least a portion of the apparent convergence may be a consequence of electrical coupling between ac- 
cumbens neurons receiving distinct inputs (O'Donnell and Grace, 1993a). However, given the comparatively low degree of variability in the rate-of-rise and amplitude of the evoked responses observed in each cell upon stimulation of these pathways, the responses are more likely due to a direct synaptic input to each cell. Furthermore, the sites of stimulation appeared to be limited to the target site, with little spread of current to adjacent regions, as shown by the failure to observe synaptic activation after stimulation of the zona incerta region, which does not project to the accumbens.

The EPSPs evoked by stimulation of each of the three sites were similar with respect to their amplitude and rise time, although they occurred at different latencies. For a given cell, measurement of the amplitude and latencies of EPSPs evoked by stimulation of the fornix were taken from the onset of the response, which occurred at a constant latency, and therefore were not contaminated by variations due to the delayed switch to the depolarized state that is present in bistable cells (see below). The mean response amplitude across all stimulation sites was approximately $14 \mathrm{mV}$ (Table 1 ). The latency to the onset of the responses was approximately $5 \mathrm{msec}$ for PFC-evoked EPSPs, $8 \mathrm{msec}$ for fornix-evoked EPSPs, and $17 \mathrm{msec}$ for amygdala-evoked EPSPs. Although the constant latency of the responses evoked by stimulation of the amygdala is typically taken as evidence of a monosynaptic response, the extraordinary long latencies for such short straight-line conduction distance argues against a monosynaptic nature for this response.

Interactions between afferent inputs and the bistable pattern of activity

As described above, most of the nucleus accumbens cells tested exhibited excitatory responses upon stimulation of hippocampal afferents. However, in the cells that initially exhibited a histahle membrane potential ( 9 of 12), a unique response was evoked: either a long-lasting switch to the depolarized state $(n=7)$ or a prolonged EPSP/plateau potential that lasted for $46-60 \mathrm{msec}$ before repolarization $(n=2)$. These responses could also be induced in these cells by delivering trains of pulses to the fornix. In contrast, following transection of the fimbria-fornix, none of the accumbens cells recorded exhibited the bistable firing pattern $(n=9)$. Stimulation of the PFC in these cells induced EPSPs that were not significantly smaller in amplitude than those evoked in intact rats. Furthermore, although $47 \%$ of the EPSPS evoked in accumbens cells in intact rats upon PFC stimulation also triggered spikes, none of the fornix-transected rats responded to PFC stimulation with evoked action potential discharge. In addition, the acute injection of lidocainc into the fornix induced a transient suppression of the depolarized state in bistable cells. Therefore, these data suggest that the hippocampal afferents to the accumbens traveling in the fornix (1) are the source of the synaptic influence that causes bistable cells to exhibit the depolarized plateau, and (2) are required to allow PFC afferent input to elicit spike discharge within the nucleus accumbens. In contrast, in sham-lesioned rats in which the fornix was spared, $67 \%$ (6 of 9) of the cells exhibited the bistable pattern and PFC stimulation evoked action potential discharge in $66 \%$ (4 of 6) of the cells tested.

In intact rats, the response to PFC stimulation was dependent on the current state of the bistable cell. Thus, stimulation of the PFC at amplitudes too low to evoke spiking in bistable cells when in their hyperpolarized state could readily evoke spike discharge in cells in which hippocampal afferent stimulation had induced a prolonged depolarization of the membrane analogous to that present in the depolarized state. Moreover, in accumbens neurons firing in the depolarized state, stimulation of the PFC was observed in seven of seven cases to cause a delayed transition to the hyperpolarized state. Although the mechanism for this is unclear, there are several possible explanations for this response. One possibility is that the PFC afferents also caused an activation of neighboring accumbens cells which in turn inhibited the cell impaled. This possibility is consistent with the presence of an EPSP-IPSP sequence in response to PFC activation, with the time course of the late IPSP being equivalent to the delay associated with the PFC stimulation-induced transition in state. However, this would not be consistent with data showing that the biphasic state is dependent solely on hippocampal input and is not affected by direct membrane hyperpolarization. A more likely possibility is that the PFC stimulation somehow truncated the duration of the synaptic volley arising from the hippocampus. Thus, it may be that fornix stimulation activates a reverberating circuit in the hippocampus that maintains activity within the hippocampus-accumbens projections (Boeijinga et al., 1993), and that this tonically activated state in the hippocampus is somehow "reset" by PFC input to this region. Indeed, stimulation of PFC has been demonstrated to induce IPSPs in subicular cells recorded in vivo (White et al., 1990).

Cells located in the dorsal striatum (i.e., the caudate-putamen) recorded in vivo also exhibit spontaneous plateau-like transitions in their baseline membrane potential (Wilson and Groves, 1981; Calabresi et al., 1990; Wilson, 1992a,b; Onn et al., 1994). However, unlike the accumbens, these transitions are not likely to be driven by hippocampal afferents since the hippocampal input to the dorsal striatum is, at best, sparse (Kelley and Domesick, 1982). Furthermore, bistable neurons were readily observed in the dorsal striatum of the fornix-transected animals (P. O'Donnell and A. A. Grace, unpublished observations). Thus, it is unclear whether the spontaneous switching reported in dorsal striatal cells is mediated by a distinct afferent system, or if the bistable pattern represents more of an interaction between cell membrane properties and neocortical synaptic input within the striatum as proposed in models of these neurons (Wilson, 1993).

One issue that should be addressed is the possibility that some of the responses generated by fornix stimulation may have actually been due to activation of septohippocampal or other afferent fibers to the accumbens that also traverse through the fornix (Lopes da Silva et al., 1990). Nonetheless, it is our belief that these responses were mediated via the subicular afferents to the accumbens for the following reasons: (1) the presence of a hcavy glutamatcrgic innervation within the accumbens that originates from the ventral subiculum and reaches the accumbens via the fimbria-fornix system (Kelley and Domesick, 1982; De France et al., 1985; Fuller et al., 1987; Boeijinga et al., 1990, $1993) ;(2)$ the similarity in the responses obtained by stimulation of the fornix with those reported by others upon delivering a stimulus to the ventral subiculum (Boeijinga et al., 1990); this conlrasts with the slower modulatory effects produced by norepinephrine and other monoaminergic fibers that are present in the fornix-fimbria system (Segal and Bloom, 1976); (3) the presence of hippocampal-like theta activity rhythms that have been recorded within the nucleus accumbens (Leung and Yim, 1993); and (4) our results showing that stimulation of other nearby structures, such as the thalamus, produce qualitatively different responses when compared to those occurring with fimbria-fornix stimulation. Another possibility that was addressed was the po- 
tential involvement of thalamic input to the accumbens. The thalamic afferents comprise a dense projection that arises from the midline thalamic nuclei (Su and Bentivoglio, 1990). One concern is that this pathway may have also been activated during stimulation of the fornix. However, although stimulation of the PV nucleus did elicit EPSPs in two of four accumbens cells tested, thalamic stimulation-dependent transitions to a depolarized state were not observed.

\section{Hippocampal gating of prefrontal cortical throughput within the accumbens and its potential relevance to schizophrenia}

It is apparent from these studies that the interaction between hippocampal and PFC inputs to accumbens neurons is complex, and there are likely to be several plausible models that can be derived from our data that may explain its functional consequences. One model that is consistent with our data proposes that the hippocampal afferents are involved in a gating mechanism that regulates information throughput within the accumbens. Thus, PFC afferents evoke a brief phasic excitatory response that by itself has a low probability of eliciting accumbens cell firing. The hippocampal input, on the other hand, induces a prolonged depolarizing plateau in a periodic manner, which appears to exert more of a modulatory influence rather than representing another phasic source of excitatory information. Under these conditions, activation of the hippocampal input causes the bistable accumbens cells to shift to the depolarized state, during which the phasic PFC input is capable of activating accumbens cell firing to ultimately affect the ventral pallidal-mediodorsal (MD) thalamic-PFC system (Lavín and Grace, 1994). Moreover, a strong PFC activation also appears to reset the bistable state, thereby preventing subsequent PFC activity from reaching the thalamus. As described, the interaction may be the functional equivalent of the arming of a one-shot gate: activation of the hippocampus-accumbens pathway sets up the accumbens to allow a burst of information throughput to flow from the PFC to the thalamus by causing the bistable accumbens cells to enter the depolarized state. After the next burst of PFC input is allowed to pass through the accumbens and onto the thalamus, the accumbens neurons are reset to the hyperpolarized state, functionally closing the gate to additional PFC inputs.

A functional interpretation of this model may provide a possible explanation for some of the characteristics reported in disorders of the PFC-accumbens system, such as schizophrenia. Thus, several studies have suggested that schizophrenics exhibit a hypofrontality syndrome (Buchsbaum et al., 1982; Berman et al., 1986; Friston, 1992; Tamminga et al., 1992), in which the PFC fails to show activation on certain cognitive tasks in which schizophrenics perform poorly, such as the Wisconsin Card Sorting Test. Furthermore, several pieces of evidence suggest that pathological changes in the hippocampus may lead to this hypofrontal state (Kovelman and Scheibel, 1984; Barta et al., 1990; Kerwin et a1., 1990; Shenton et al., 1992; Lipska et al., 1993; Ulas and Cotman, 1993; Waddington, 1993). The accumbens itself is contained within a feedback loop system (Fig. 15A), in which the accumbens exerts control over the ventral pallidum, which in turn sends inhibitory projections to the MD nucleus of the thalamus (Young et al., 1984; Haber et al., 1985; Lavín and Grace, 1994). The MD has excitatory interconnexions with the PFC, which supplies excitatory input to the nucleus accumbens. Our results provide evidence that the PFC by itself is not capable of activating nucleus accumbens cell firing. As a result of the absence of hippocampal-PFC activation of accumbens cells, the
A

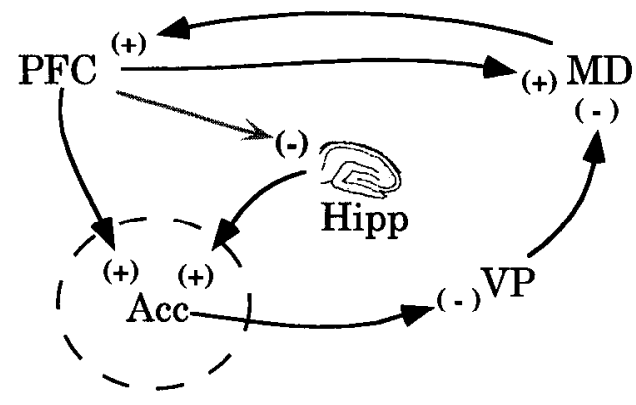

B1
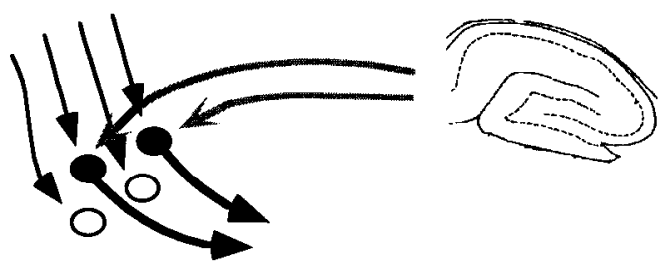

B2
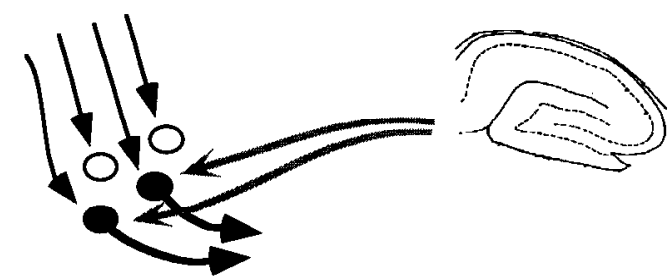

Figure 15. Model of hippocampal enabling of accumbens distributed units. A, Hippocampai (Hipp) input onto accumbens neurons converges with excitatory input from the PFC, and their output is conveyed via the ventral pallidum $(V P)$ and mediodorsal thalamic nucleus $(M D)$ back to the PFC. $B$, Two sets of related accumbens information processing units are represented by the open or solid circles. All of the neurons receive PFC input as well as excitatory input from other sources such as the hippocampus (gray arrows). BI, In a given spatiotemporal context, the hippocampal input, arriving via the fornix, may selectively enable a subset of units within the accumbens to relay cortical information to the ventral pallidum by inducing a switch to the depolarized (active) state (solid circles). Only the units activated by hippocampal afferent stimulation are capable of eliciting spikes in response to PFC input, and therefore are the only units that can relay cortical information to their targets. $B 2$, In contrast, in a different spatiotemporal context in which a unique set of behavioral responses are required, the hippocampal input will select a different subset of units for activation. The units being activated are likely to represent the clusters of neurons that are required to evoke a coordinated function, given the high incidence of electrical coupling present between neurons within the accumbens (O'Donnell and Grace, 1993a).

subsequent disinhibition of the VP-MD projection would contribute to the hypofrontality via a decrease in activity within the MD-PFC circuit (Lavín and Grace, 1994). On the other hand, in normals in which the hippocampoaccumbens pathway is active, nucleus accumbens cells should be capable of responding to PFC input, resulting in an upregulation of PFC-accumbens throughput.

One possible function of such a selective gate could relate to the hypothesized role of the hippocampus in regulating contextsensitive cues. The hippocampus has been proposed to play a role in providing a spatial context frame of reference (O'Keefe and Dostrovsky, 1971; O’Keefe, 1979; Eichenbaum et al., 1989; 
Kesner et al., 1993; Wilson and McNaughton, 1993) and in the motivation to explore novel environments (Jarrard, 1968). In this way, the hippocampus may enable transit of information from the PFC to the accumbens in a context-dependent manner (Fig. $15 B$ ). Indeed, recent studies have shown that, as with hippocampal neurons, the activity of a set of accumbens cells is correlated with the location of the animal in space ("place cells"; Lavoie and Mizumori, 1994). A disruption of this system, as is proposed to occur in schizophrenia, may interfere with this context-sensitive gating, potentially leading to increased distractibility and an inability to screen out irrelevant information (Myles-Worsley et al., 1991), a greater incidence of perseverative errors (Fey, 1951), and the out-of-context responses that are characteristic of these patients (Chapman et al., 1964; de Silva and Hemsley, 1977).

\section{References}

Aldridge JW, Gilman S (1991) The temporal structure of spike trains in the primate basal ganglia: afferent regulation of bursting demonstrated with precentral cerebral cortical ablation. Brain Res 543:123136.

Amzica F, Núñez A, Steriade M (1992) Delta frequency (1-4 Hz) oscillations of perigeniculate thalamic neurons and their modulation by light. Neuroscience 51:285-294.

Arnold SE, Hyman BT, Van Hoesen GW, Damasio AR (1991) Some cytoarchitectural abnormalities of the entorhinal cortex in schizophrenia. Arch Gen Psychiatry 48:625-632.

Barta PE, Pearlson GD, Powers RE, Richards SS, Tune LE (1990) Auditory hallucinations and smaller superior temporal gyral volume in schizophrenia. Am J Psychiatry 147:1457-1462.

Berman KF, Weinberger DR (1991) Prefrontal dopamine and defect symptoms in schizophrenia. In: Negative schizophrenic symptoms: pathophysiology and clinical implications (Greden JF, Tandon R, eds), pp 83-95. Washington, DC: American Psychiatric

Berman KF, Zec RF, Weinberger DR (1986) Physiologic dysfunction of dorsolateral prefrontal cortex in schizophrenia. II. Role of neuroleptic treatment, attention, and mental effort. Arch Gen Psychiatry 43:126-135.

Boeijinga PH, Pennartz CMA, Lopes da Silva FH (1990) Paired-pulse facilitation in the nucleus accumbens following stimulation of subicular inputs in the rat. Neuroscience 35:301-311.

Boeijinga PH, Mulder AB, Pennartz CMA, Manshanden I, Lopes da Silva FH (1993) Responses of the nucleus accumbens following fornix/fimbria stimulation in the rat. Identification and long-term potentiation of mono- and polysynaptic pathways. Neuroscience 53:10491058 .

Bogerts B, Lieberman JA, Ashtari M, Bilder RM, Degreef G, Lerner G, Johns C, Masiar S (1993) Hippocampus-amygdala volumes and psychopathology in chronic schizophrenia. Biol Psychiatry 33:236246.

Buchsbaum MS, Ingvar DH, Kessler R, Waters RN, Cappelletti J, van Kammen DP, King C, Johnson JL, Manning RG, Flynn RW, Mann LS, Bunney WE, Sokoloff L (1982) Cerebral glucography with positron tomography. Use in normal subjects and in patients with schizophrenia. Arch Gen Psychiatry 39:251-259.

Buchsbaum MS, Haier RJ, Potkin SG, Nuechterlein K, Bracha HS, Katz M, Lohr J, Wu J, Lottenberg S, Jerabek PA, Trenary M, Tafalla R, Reynolds C, Bunney WE (1992) Frontostriatal disorder of cerebral metabolism in never-medicated schizophrenics. Arch Gen Psychiatry 49:935-942.

Calabresi P, Mercuri NB, Stefani A, Bernardi G (1990) Synaptic and intrinsic control of membrane excitability of neostriatal neurons. I An in vivo analysis. J Neurophysiol 63:651-662.

Calabresi P, Mercuri NB, De Murtas M, Bernardi G (1991) Involvement of GABA systems in feedback regulation of glutamate- and GABA- mediated synaptic potentials in rat neostriatum. J Physiol (Lond) 440:581-599.

Callaway CW, Hakan RL, Henriksen SJ (1991) Distribution of amygdala input to the nucleus accumbens septi: an electrophysiological investigation. J Neural Transm [Gen Sect] 83:215-225.

Carpenter WT, Buchanan RW (1994) Schizophrenia. New Engl J Med $330: 681-690$
Chang HT, Kitai ST (1986) Intracellular recordings from rat nucleus accumbens neurons in vitro. Brain Res 366:392-396.

Chapman L, Chapman J, Miller G (1964) A theory on verbal behavior in schizophrenia. In: Progress in experimental personality research, Vol I (Maher B, ed), pp 49-77. New York: Academic.

Chiodo LA, Bunney BS (1983) Typical and atypical neuroleptics: differential effects of chronic administration on the activity of $A 9$ and A10 midbrain dopaminergic neurons. J Neurosci 3:1607-1619.

Cowan RL, Wilson CJ (1994) Spontaneous firing patterns and axonal projections of single corticostriatal neurons in the rat medial agranular cortex. J Neurophysiol 71:17-32.

De France JF, Marchand JF, Sikes RW, Chronister RB, Hubbard JI (1985) Characterization of fimbria input to nucleus accumbens. J Neurophysiol 54:1553-1567.

de Silva WP, Hemsley DR (1977) The influence of context on language perception in schizophrenia. Br J Soc Clin Psychol 16:337-345.

Domesick VB (1981) Further observations on the anatomy of nucleus accumbens and caudatoputamen in the rat: similarities and contrasts. In: The neurobiology of the nucleus accumbens (Chronister RB, DeFrance JF, eds), pp 7-39. Brunswick, ME: Hauer Institute.

Eichenbaum H, Wiener SI, Shapiro ML, Cohen NJ (1989) The orga nization of spatial coding in the hippocampus: a study of neural ensemble activity. J Neurosci 9:2764-2775.

Falkai P, Bogerts B (1986) Cell loss in the hippocampus of schizophrenics. Eur Arch Psychiatry Neural Sci 236:154-161.

Fey ET (1951) The performance of young schizophrenics and young normals on the Wisconsin Card Sorting Test. J Consult Psychol 15: 311-319.

Friston KJ (1992) The dorsolateral prefrontal cortex, schizophrenia and PET. J Neural Transm [Suppl] 37:79-93.

Fuller TA, Russchen FT, Price JL (1987) Sources of presumptive glutamatergic/aspartergic afferents to the rat ventral striatopallidal region. J Comp Neurol 258:317-338.

Grace AA (1991) Phasic versus tonic dopamine release and the modulation of dopamine system responsivity: a hypothesis for the etiology of schizophrenia. Neuroscience 41:1-24.

Grace AA (1992) The depolarization block hypothesis of neuroleptic action: implications for the etiology and treatment of schizophrenia. J Neural Transm [Suppl] 36:91-131.

Grace AA, O'Donnell P (1994) Prefrontal cortical input to nucleus accumbens neurons is differentially modulated by dopaminergic and hippocampal afferents. Dopamine ' 94 , in press.

Groenewegen HJ, Becker NEHM, Lohman AHM (1980) Subcortical afferents of the nucleus accumbens septi in the cat, studied with retrograde axonal transport of horseradish peroxidase and bisbenzimid. Neuroscience 5:1903-1916.

Gur RE, Pearlson GD (1993) Neuroimaging in schizophrenia research. Schizophr Bull 19:337-353.

Haber SN, Groenewegen HJ, Grove EA, Nauta WJH (1985) Efferent connections of the ventral pallidum: evidence of a dual striatopalHdofugal pathway. J Comp Neurol 235:322-335.

Hull CD, Bernardi G, Buchwald NA (1970) Intracellular responses of caudate neurons to brain stem stimulation. Brain Res 22:163-179.

Jahnsen H, Llinás R (1984) Ionic basis for the electroresponsiveness and oscillatory properties of guinea-pig thalamic neurones in vitro. $\mathbf{J}$ Physiol (Lond) 349:227-247.

Jarrard LE (1968) Behavior of hippocampal lesioned rats in home cage and novel situations. Physiol Behav 3:65-70.

Johansson O, Hökfelt T (1981) Nucleus accumbens: transmitter histochemistry with special reference to peptide-containing neurons. In: The neurobiology of the nucleus accumbens (Chronister RB, DeFrance JF, eds), pp 147-171. Brunswick, ME: Hauer Institute.

Kawasaki Y, Maeda Y, Urata K, Higashima M, Yamaguchi N, Suzuki M, Takashima T, Ide Y (1993) A quantitative magnetic resonance imaging study of patients with schizophrenia. Eur Arch Psychiatry Clin Neurosci 242:268-272.

Kelley AE, Domesick VB (1982) The distribution of the projection from the hippocampal formation to the nucleus accumbens in the rat: an anterograde- and retrograde-horseradish peroxidase study. Neuroscience 7:2321-2335.

Kerwin R, Patel S, Meldrum B (1990) Quantitative autoradiographic analysis of glutamate binding sites in the hippocampal formation in normal and schizophrenic brain post mortem. Neuroscience 39:2532 .

Kesner RP, Bolland BL, Dakis M (1993) Memory for spatial locations, 
motor responses, and objects: triple dissociation among the hippocampus, caudate nucleus, and extrastriate visual cortex. Exp Brain Res 93:462-470.

Kita H, Kitai ST (1990) Amygdaloid projections to the frontal cortex and the striatum in the rat. J Comp Neurol 298:40-49.

Kitai ST, Surmeier DJ (1993) Cholinergic and dopaminergic modulation of potassium conductances in ncostriatal ncurons. In: Advances in neurology (Narabayashi $\mathrm{H}$, Nagatsu T, Yanagisawa N, Mizuno Y, eds), pp 40-52. New York: Raven.

Kombian SB, Malenka RC (1994) Simultaneous LTP of non-NMDAand LTD of NMDA-receptor-mediated responses in the nucleus accumbens. Nature 368:242-246.

Kovelman JA, Scheibel AB (1984) A neurohistological correlate of schizophrenia. Biol Psychiatry 19:1601-1917.

Lavín A, Grace AA (1994) The modulation of dorsal thalamic cell activity by the ventral pallidum: its role in the regulation of thalamocortical activity in the basal ganglia. Synapse 18:104-127.

Lavoie AM, Mizumori SJY (1994) Spatial, movement- and rewardsensitive discharge by medial ventral striatum neurons in rats. Brain Res 638:157-168.

Leung LS, Yim CYC (1993) Khythmic delta-frequency activities in the nucleus accumbens of anesthetized freely moving rats. Can J Physiol Pharmacol 71:311-320.

Liddle PF, Morris DL (1991) Schizophrenic syndromes and frontal lobe performance. Br J Psychiatry 158:340-345.

Liddle PF, Friston KJ, Frith CD, Frachowiak RSJ (1992a) Cerebral blood flow and mental processes in schizophrenia. J R Soc Med 85: 224-227.

Liddle PF, Friston KJ, Frith CD, Hirsch SR, Jones T, Frachowiak RSJ (1992b) Patterns of cerebral blood flow in schizophrenia. Br J Psychiatry 160:179-186.

Lipska BK, Jaskiw GE, Weinberger DR (1993) Postpuberal emergence of hyperresponsiveness to stress and to amphetamine after neonatal excitotoxic hippocampal damage: a potential animal model of schizophrenia. Neuropsychopharmacology 9:67-75.

Llinás R, Yarom Y (1981) Electrophysiology of mammalian inferior olivary neurones in vitro. Different types of voltage-dependent ionic conductances. J Physiol (Lond) 315:549-567.

Llinás RR (1988) The intrinsic electrophysiological properties of mammalian neurons: insights into central nervous systen function. Science 242:1654-1664.

Lopes da Silva FH, Witter MP, Boeijinga PH, Lohman AH (1990) Anatomic organization and physiology of the limbic cortex. Physiol Rev 70:453-511.

McCormick DA. Pape H-C (1990) Properties of a hyperpolarizationactivated cation current and its role in rhythmic oscillation in thalamic relay neurones. J Physiol (Lond) 431:291-318.

Meredith GE, Pennartz CMA, Groenewegen HJ (1993) The cellular framework for chemical signalling in the nucleus accumbens. In: Chemical signaling in the basal ganglia (Arbuthnott GW, Emson PC, eds), pp 3-24. Amsterdam: Elsevier.

Mittleman G, LeDuc PA, Whishaw IQ (1993) The role of D1 and D2 receptors in the heightened locomotion induced by direct and indirect dopamine agonists in rats with hippocampal damage: an animal analogue of schizophrenia. Behav Brain Res 55:253-267.

Mogenson GJ, Yang CR (1991) The contribution of basal forebrain to limbic-motor integration and the mediation of motivation to action. In: The basal forebrain (Napier TC, ed), pp 267-290. New York: Plenum.

Mogenson GM, Yim CC (1991) Neuromodulatory functions of the mesolimbic dopamine system: electrophysiological and behavioral studies. In: The mesolimbic dopamine system: from motivation to action (Willner P, Scheel-Krüger J, eds), pp 105-130. New York: Wiley.

Mogenson GJ, Jones DL, Yim CY (1980) From motivation to action: functional interface between limbic system and the motor system. Prog Neurobiol 14:69-97.

Myles-Worsley M, Johnston WA, Wender PH (1991) Spontaneous selective attention in schizophrenia. Psychiatry Res 39:167-179.

Nisenbaum ES, Berger TW (1992) Functionally distinct subpopulations of striatal neurons are differentially regulated by GABAergic and dopaminergic inputs. I. An in vivo analysis. Neuroscience 48:561578 .

O'Donnell P, Grace AA (1993a) Dopaminergic modulation of dye cou- pling between neurons in the core and shell regions of the nucleus accumbens. J Neurosci 13:3456-3471.

O'Donnell P, Grace AA (1993b) Physiological and morphological properties of accumbens core and shell neurons recorded in vitro. Synapse 13:135-160.

O'Donnell P, Grace AA (1994a) Tonic $\mathrm{D}_{2}$-mediated attenuation of cortical excitation in nuclcus accumbens neurons recorded in vitro. Brain Res 634:105-112.

O'Donnell P, Grace AA (1994b) Hippocampal gating of prefrontal cortical input onto nucleus accumbens neurons recorded intracellularly in vivo. Soc Neurosci Abstr 20:566.

O'Keefe J (1979) A review of the hippocampal place cells. Prog Neurobiol 13:419-439.

O'Keefe J, Dostrovsky J (1971) The hippocampus as a spatial map. Preliminary evidence from unit activity in the freely-moving rat. Brain Res 34:171-175.

Onn S-P, Berger TW, Grace AA (1994) Identification and characterization of striatal cell subtypes using in vivo intracellular recording in rats. I. Basic physiology and response to corticostriatal fiber stimulation. Synapse 16:161-180.

Paxinos $G$, Watson $C$ (1986) The rat brain in stereotaxic coordinates. Sydney: Academic.

Pennartz CMA, Boeijinga PH, Kitai ST, Lopes da Silva FH (1991) Contribution of NMDA receptors to postsynaptic potentials and paired-pulse facilitation in identified neurons of the rat nucleus accumbens in vitro. Exp Brain Res 86:190-198.

Pennartz CMA, Dolleman-van der Weel MJ, Kitai ST, Lopes da Silva FH (1992a) Presynaptic dopamine D1 receptors attenuate excitatory and inhibitory limbic inputs to the shell region of the rat nucleus accumbens. J Neurophysiol 67:1325-1334.

Pennartz CMA, Dolleman-Van der Weel MJ, Lopes da Silva FH (1992b) Differential membrane properties and dopamine effects in the shell and core of the rat nucleus accumbens studied in vitro. Neurosci Lett 136:109-112.

Pennartz CMA, Ameerun RF, Groenewegen HJ, Lopes da Silva FH (1993) Synaptic plasticity in an in vitro slice preparation of the rat nucleus accumbens. Eur J Neurosci 5:107-117.

Pettegrew JW, Keshavan M, Panchalingbam K, Strychor S, Kaplan DB, Tretta MG, Allen M (1991) Alterations in brain high-energy phosphate and membrane phospholipid metabolism in first-episode, drugnaive schizophrenics. Arch Gen Psychiatry 48:563-568.

Raine A, Lencz T, Reynolds GP, Harrison G, Sheard C, Medley I, Reynolds LM, Cooper JE (1992) An evaluation of structural and functional prefrontal deficits in schizophrenia: MRI and neuropsychological measures. Psychiatry Res 45:123-137.

Reinstein DK, Hannigan JH, Isaacson RL (1982) Time course of certain behavioral changes after hippocampal damage and their alteration by dopaminergic intervention into nucleus accumbens. Pharmacol Biochem Behav 17:193-202.

Robbins TW (1990) The case for frontostriatal dysfunction in schizophrenia. Schizophir Bull 16:391-402.

Seeman P (1987) Dopamine receptors and the dopamine hypothesis of schizophrenia. Synapse 1:133-152.

Segal M, Bloom FE (1976) The action of norepinephrine in the rat hippocampus. III. Hippocampal cellular responses to locus coeruleus stimulation in the awake rat. Brain Res 107:499-511.

Sesack SR, Deutch AY, Roth RH, Bunney BS (1989) Topographical organization of the efferent projections of the medial prefrontal cortex in the rat: an anterograde tract-tracing study with Phaseolus vulgaris leucoagglutinin. J Comp Neurol 290:213-242.

Shapiro RM (1993) Regional neuropathology in schizophrenia: where are we? Where are we going? Schizophr Res 10:187-239.

Shenton ME, Kikinis R, Jolesz FA, Pollak SD, LeMay M, Wible CG, Hokama H, Martin J, Matcalf D, Coleman M, McCarley RW (1992) Abnormalities of the left temporal lobe and thought disorder in schizophrenia. A quantitative magnetic resonance imaging study. New Engl J Med 327:604-612.

Sherman AD, Davidson AT, Baruah S, Hegwood TS, Waziri R (1991) Evidence of glutamatergic deficiency in schizophrenia. Neurosci Lett 121:77-80.

Snyder SH (1973) Amphetamine psychosis: a model of schizophrenia mediated by catecholamines. Am J Psychiatry 130:61-67.

Stafstrom CE, Schwindt PC, Flatman JA, Crill WE (1984) Properties of subthreshold response and action potential recorded in layer $\mathrm{V}$ 
neurons from cat sensorimotor cortex in vitro. $\mathrm{J}$ Neurophysiol 52: 244-263.

Steriade M, Llinás RR (1988) The functional states of the thalamus and the associated neuronal interplay. Physiol Rev 68:649-742.

Steriade M, Nuñez A, Amzica F (1993) A novel slow $(<1 \mathrm{~Hz}$ ) oscillation of neocortical neuron in vivo: depolarizing and hyperpolarizing components. J Neurosci 13:32552-3265.

Su H-S, Bentivoglio M (1990) Thalamic midline cell populations projecting to the nucleus accumbens, amygdala, and hippocampus in the rat. J Comp Neurol 297:582-593.

Suddath RL, Christison GW, Torrey EF, Casanova MF, Weinberger DR (1990) Anatomical abnormalities in the brains of monozygotic twins discordant for schizophrenia. New Engl J Med 322:789-794.

Sugimori M, Preston RJ, Kitai ST (1978) Response properties and electrical constants of caudate neurons in the cat. J Neurophysiol 41: $1662-1675$.

Swanson LW, Cowan WM (1975) A note on the connections and development of the nucleus accumbens. Brain Res 92:324-330.

Tamminga CA, Thaker GK, Buchanan R, Kirkpatrick B, Alphs LD, Chase TN, Carpenter WT (1992) Limbic system abnormalities identified in schizophrenia using positron emission tomography with fluorodeoxyglucose and neocortical alterations with deficit syndrome. Arch Gen Psychiatry 49:522-530.

Uchimura N, North RA (1991) Baclofen and adenosine inhibit synaptic potentials mediated by gamma-aminobutyric acid and glutamate release in rat nucleus accumbens. J Pharmacol Exp Ther 258:663-668.

Uchimura N, Higashi H, Nishi S (1986) Hyperpolarizing and depolarizing actions of dopamine via D-1 and D-2 receptors on nucleus accumbens neurons. Brain Res 375:368-372.

Uchimura N, Cherubini E, North RA (1989a) Inward rectification in rat nucleus accumbens neurons. J Neurophysiol 62:1280-1286.

Uchimura N, Higashi H, Nishi S (1989b) Membrane properties and synaptic responses of the guinea pig nucleus accumbens neurons in vitro. J Neurophysiol 61:769-779.

Ułas J, Cotman CW (1993) Excitatory amino acid receptors in schizophrenia. Schizophr Bull 19:105-117.

Waddington JL (1993) Schizophrenia: developmental neuroscience and pathobiology. Lancet 341:531-536.

Weinberger DR (1987) Implications of normal brain development for the pathogenesis of schizophrenia. Arch Gen Psychiatry 44:660-669.

Weinberger DR, Berman KF, Suddath R, Torrey EF (1992) Evidence of dysfunction of a prefrontal-limbic network in schizophrenia: a magnetic resonance imaging and regional cerebral blood flow study of discordant monozygotic twins. Am J Psychiatry 149:890-897.

White FJ, Wang RY (1983) Differential effects of classical and atypical antipsychotic drugs on $\mathrm{A} 9$ and A10 dopamine neurons. Science 221: $1054-1057$

White TD, Tan AM, Finch DM (1990) Functional reciprocal connections of the rat entorhinal cortex and subicular complex with the medial frontal cortex: an in vivo intracellular study. Brain Res 533: 95-106.

Wilson CJ (1992a) Dendritic morphology, inward rectification, and the functional properties of neostriatal neurons. In: Neural nets: foundations to applications. Single neuron computation (McKenna T, Davis J, Zornetzer SF, eds), pp 141-171. San Diego: Academic.

Wilson CJ (1992b) Voltage-gated currents contribute to spontaneous membrane potential shifts in neostriatal projection neurons. Soc Neurosci Ahstr 18:849.

Wilson CJ (1993) The generation of natural firing patterns in neostriatal neurons. In: Chemical signaling in the basal ganglia (Arbuthnott GW, Emson PC, eds), pp 277 297. Amsterdam: Elsevier.

Wilson CJ, Groves PM (1981) Spontaneous firing patterns of identified spiny neurons in the rat neostriatum. Brain Res 220:67-80.

Wilson MA, McNaughton BL (1993) Dynamics of the hippocampal ensemble code for space. Science 261:1055-1058.

Yang CR, Mogenson GJ (1984) Electrophysiological responses of neurones in the accumbens nucleus to hippocampal stimulation and the attenuation of the excitatory responses by the mesolimbic dopaminergic system. Brain Res 324:69-84.

Yang CR, Mogenson GJ (1986) Dopamine enhances terminal excitability of hippocampal-accumbens neurons via D2 receptor: role of dopamine in presynaptic inhibition. J Neurosci 6:2470-2478.

Yang CR, Mogenson GJ (1987) Hippocampal signal transmission to the pedunculopontine nucleus and its regulation by dopamine $\mathrm{D}_{2}$ receptors in the nucleus accumbens: an electrophysiological and behavioral study. Neuroscience 23:1041-1055.

Yim CY, Mogenson GJ (1982) Response of nucleus accumbens neurons to amygdala stimulation and its modification by dopamine. Brain Res 239:401-415.

Yim CY, Mogenson GJ (1986) Mesolimbic dopamine projection modulates amygdala-evoked EPSP in nucleus accumbens neurons: an in vivo study. Brain Res 369:347-352.

Yim CY, Mogenson GJ (1988) Neuromodulatory action of dopamine in the nucleus accumbens: an in vivo intracellular study. Neuroscience 26:403-415.

Yim CY, Mogenson GJ (1989) Low doses of accumbens dopamine modulate amygdala suppression of spontaneous exploratory activity in rats. Brain Res 477:202-210.

Young WS, Alheid GF, Heimer L (1984) The ventral pallidal projection to the mediodorsal thalamus: a study with fluorescent retrograde tracers and immunohistofluorescence. J Neurosci 4:1626-1638. 